\title{
Changing Patterns of Income Inequality in U.S. Counties, 1970-2000 ${ }^{1}$
}

\author{
Stephanie Moller \\ University of North Carolina, \\ Charlotte \\ François Nielsen \\ University of North Carolina, Chapel Hill
}

Arthur S. Alderson

Indiana University, Bloomington

The upswing in economic inequality that has affected a number of advanced industrial societies in the late 20th century has been particularly conspicuous in the United States. The authors explore its causes using data on the distribution of family income in 3,098 U.S. counties in 1970, 1980, 1990, and 2000. The authors build a model of within-county income inequality that assumes that distribution processes involving labor market and sociodemographic variables operate primarily at the county level and those involving the political and institutional context operate primarily at the state level. Multilevel methods are used to distinguish county cross-sectional, state cross-sectional, and longitudinal effects on inequality. The authors find that, when features of the state-level institutional and political context are associated with inequality, these effects are larger longitudinally than cross-sectionally. A range of other factors, including economic development, labor force changes, shifts in the racial/ethnic and gender composition of the labor force, educational expansion, and urbanization are found to have comparatively large effects, both longitudinally and cross-sectionally.

\section{INEQUALITY TRENDS IN THE LATE 20TH CENTURY}

One of the most intriguing socioeconomic trends of the last decades of the 20th century is the upswing in income inequality that was first noted

\footnotetext{
${ }^{1}$ The authors would like to acknowledge the helpful comments and suggestions of Phil Gibbs, David Lowery, the late Rachel Rosenfeld, John Stephens, and the AJS reviewers. Direct all correspondence to Stephanie Moller, Department of Sociology, University of North Carolina, 9201 University City Boulevard, Charlotte, North Carolina 28223. E-mail: smoller@uncc.edu

(C) 2009 by The University of Chicago. All rights reserved. 0002-9602/2009/11404-0004\$10.00
} 
American Journal of Sociology

in the United States and soon dubbed, somewhat inevitably, the "Great U-turn" (Harrison and Bluestone 1988). To recapitulate some of the stylized facts: inequality in the distribution of family and household incomes began rising in the United States in the early 1970s; inequality in the distribution of wages began increasing a few years later. It was eventually realized that inequality was also rising in a number of advanced industrial societies, with the sharpest upswings affecting the United Kingdom and the United States (Freeman and Katz 1995, p. 13). For example, a study of OECD (Organization for Economic Cooperation and Development) countries over the period 1967-92 detects a U-turn or a monotonic upward inequality trend in 10 out of 16 cases (Alderson and Nielsen 2002).

The inequality upswing has captured the attention of social science researchers across the disciplines of economics, sociology, and political science for several reasons. First, the upswing represented a reversal of a long period of declining inequality during the first part of the 20th century, both in the United States and in many advanced industrial countries (Morris and Western 1999; Lindert 2000). By 1982, for example, inequality in the distribution of family incomes in the United States had surpassed the 1950 level, which had been the highest since record keeping began in 1947. Second, the upswing appeared to shatter the dominant model of the evolution of inequality in the course of economic development - the celebrated inverted U-curve relating inequality to development conjectured by Kuznets (1955; see also Lindert and Williamson 1985). Third, in the context of the ideological debate of the waning years of the Cold War, the inequality upswing provided a morality tale about the failings of Western industrial capitalism, and indeed, scholars with a critical perspective were among the first to notice, name, and analyze the phenomenon (Bluestone and Harrison 1982; Harrison and Bluestone 1988). Finally, the sheer relentlessness of the upward inequality trend in the United States over a span of decades and its apparent generality across a range of advanced industrial countries suggested that the underlying process might be an inherent feature of late capitalist development.

In this article we examine patterns of geographical variation and trends over the 1970-2000 period of inequality in the distribution of family incomes within counties of the United States. Figures 1 and 2 introduce the object of our analysis. Figure 1 presents the map of family income inequality in 1970. We note that the pattern is largely consistent with classic human ecological expectations regarding the geographical distribution of inequality in the United States. We see relatively low inequality in broad swaths of the Midwest and the Northeast; the far West is also relatively egalitarian. On the East Coast we see the black belt of inequality along the lowlands of the Southeast and the Gulf Coast and then up the Mississippi Valley (Wimberley and Morris 1997). Immediately inland from 


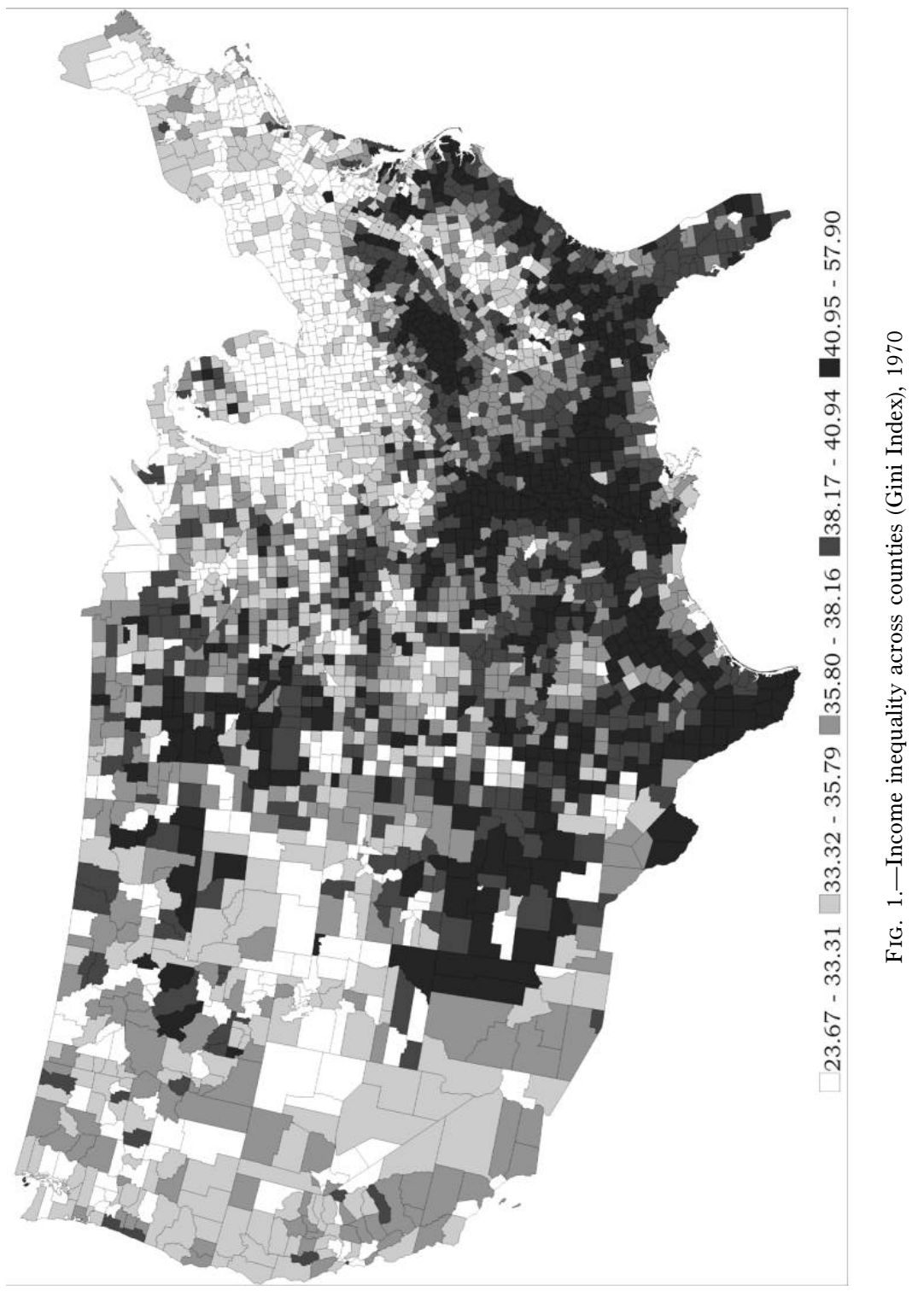




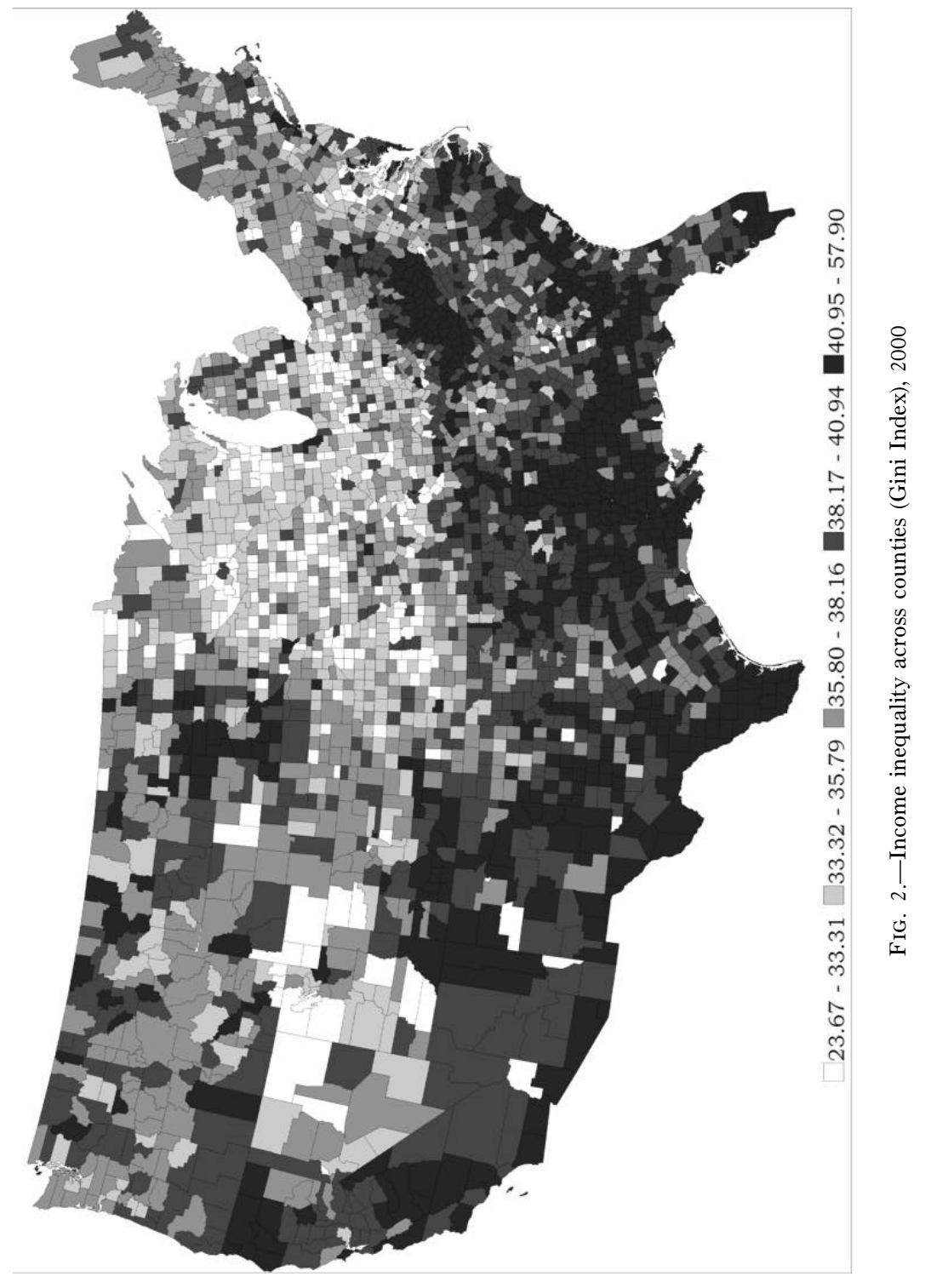


the southern East Coast and parallel to it is a band of reduced inequality corresponding to the more industrial Piedmont. Still further inland a zone of Appalachian inequality is visible.

Figure 2 presents the map of family income inequality 30 years later, in 2000. By this time inequality has risen on both coasts and, to some extent, in the Midwest too (notably, in the urbanized area along the southern tip of Lake Michigan, where some of the collar counties of Chicago have become visibly more unequal). The zone of higher inequality along the Mexican border that was incipient in 1970 has become more pronounced. By contrast, the central zone of comparatively lower inequality has moved further west toward the center of the country. The black belt and the Piedmont-Appalachian alternation are still visible.

In essence, then, what we propose to investigate in this article are the social mechanisms underlying the geographical variation in inequality represented by variation in shading in the maps, as well as the temporal variation implicit in the changes in the inequality map between 1970 and 2000. Four relatively distinct literatures bearing on inequality trends in the late 20th century inform our project. Two of these literatures focus on inequality of wages rather than household or family incomes. While wages are not the same as income, and processes affecting the distributions of wages and incomes are certainly not identical, it is quite plain that a process that, say, increases inequality in the distribution of wages will often increase inequality in the distribution of incomes (Autor, Katz, and Kearney 2005). Thus, these literatures on inequality of wages are relevant to our study of family income inequality.

The first literature we address, which is centered in labor economics, has focused on the causes of the inequality upswing in the distribution of wages in the United States. A principal hypothesis in this literature is that wage inequality has increased because of skill-biased technological change, in which technological advances, most notably the advent and mass production of the computer, have increased demand (and thus wages) for highly educated and (net of education) highly skilled workers (Bound and Johnson 1992; Levy and Murname 1992). A significant piece of evidence for this hypothesis is that the supply of highly educated workers increased during a period when their wages also increased, suggesting an increase in demand for their labor. Studies have found that this increased demand has resulted from skill upgrading in industries that utilize computers and from greater investment in computers among manufacturing industries (Berman, Bound, and Griliches 1994; Autor, Katz, and Krueger 1998). Skill-biased technological change has also been identified as an important determinant of income inequality in a broader historical context (Williamson and Lindert 1980).

Critics contend that while technological change helps explain changes 
American Journal of Sociology

in wage inequality, particularly during the 1980 s, it is an insufficient explanation of the secular rise in inequality (DiPrete 2005). For instance, Card and DiNardo (2002) identify an institutional basis of inequality by implicating the minimum wage as the key source of rising inequality in the United States, claiming that the change in the real value of the minimum wage over time explains $90 \%$ of the change in the normalized 90-10 wage gap. Autor et al. (2005) concede that the decline in the real value of the minimum wage helps explain changes at the bottom end of the income distribution but maintain that technological shifts explain the rise in inequality at the upper tail of the wage distribution (see also Lee 1999).

A second literature, also centered in labor economics, focuses on comparing wage distribution processes across OECD countries. Comparative research on wage inequality has accumulated to the point that some authors have proclaimed the emergence of a "unified theory" that would simultaneously explain late 20th-century trends in wage inequality, real wages, and unemployment across developed countries. The unified theory attributes inequality trends to the interplay of exogenous shocks affecting labor supply and demand in combination with marked differences in the institutional contexts characterizing OECD nations (Wood 1994; Blank 1998; Blau and Kahn 2002; DiPrete et al. 2006). In this perspective, for example, skill-biased technological change can have different, even contradictory, effects on inequality depending upon the institutional context.

A third literature consists of cross-national research on household and family income inequality in OECD countries. This literature in many ways echoes the comparative research on wages. It also finds inequality (and other distributional outcomes such as poverty) to be associated with a combination of developmental factors, globalization-related trends, and political and institutional arrangements including welfare generosity, strength of the social democratic tradition, union power, and centralized wage-bargaining institutions (Gustafsson and Johansson 1999; Alderson and Nielsen 2002; Bradley et al. 2003; Brady 2003; Moller et al. 2003). Cross-national research on family and household income inequality, while it does not approach the theoretical sophistication of the cross-national labor economics literature on wages and sometimes challenges insights developed in that literature, tends to identify similar sources of inequality. Sociodemographic variables, such as the age distribution and the composition of households, play a more central role in the literature on income inequality, as opposed to the one on earnings inequality, because they produce variation in income among households and families that is unrelated to earnings. ${ }^{2}$

${ }^{2}$ This point is illustrated by the finding that, in the United States, change in male- 
In this article we build most directly on a fourth literature that focuses on the determinants of family and household income inequality within U.S. counties (Tomaskovic-Devey and Roscigno 1996; Nielsen and Alderson 1997, 2001; Lobao and Hooks 2003; Moller 2003) or within U.S. states (Jacobs 1985). We study trends in inequality of the distribution of family income in nearly 3,100 U.S. counties over the four decennial censuses from 1970 to 2000. While this literature attributes variation in inequality across counties to factors similar to those identified in the crossnational literatures, including economic development and demographic characteristics, we propose that it has not adequately incorporated the state-level institutional and policy context. ${ }^{3}$

Beyond mere parochial interest, our motivation in studying income inequality within U.S. counties is threefold. First, we want to assess the extent to which wage-setting and institutional and political factors that have been found to be important determinants of economic inequality in cross-national studies of industrial countries might also explain part of the variation in inequality across local units (counties) within a single advanced society. As discussed earlier, the role of institutional and policy factors, such as the value of the minimum wage, in inequality in the United States is controversial (Card and DiNardo 2002; Autor et al. 2005). While it may certainly be the case that states within the United States do not differ institutionally and politically to the same degree that nations do, and thus that institutional effects on inequality across U.S. states should be expected to be less pronounced than those across nations, researchers have found that variations in the institutional and political orientation of the 50 U.S. states alter levels of income and risks of impoverishment for families and households (Hicks, Friedland, and Johnson 1978; Moller 2003, 2008). Thus, we want to give institutional and political factors a fair chance at explaining variance in economic inequality, assuming such effects are to be observed.

Second, we see a need to integrate literatures on inequality trends that have invoked distinct sets of mechanisms in accounting for inequality:

female earnings inequality only explains one-third of the change in family income inequality from 1979 to 1996, with sociodemographic variables explaining a substantial portion of the remaining variance (Burtless 1999).

${ }^{3}$ Research described in this article continues and extends the county-based research of Nielsen and Alderson (1997) by focusing on the role of the state institutional and political context (using measures of union density, voter turnout, political competition, legislative professionalism, spending on welfare and public education, and state policies related to the minimum wage) in the generation of inequality. We augment the earlier panel with the 2000 data and use multilevel statistical methodology to distinguish county-level, state-level, and longitudinal effects on income inequality. We also provide a thorough theoretical and methodological reformulation in view of the recent literature on income inequality. 


\section{American Journal of Sociology}

studies of U.S. wage inequality trends in labor economics, cross-national studies of wage inequality that have produced the unified theory, crossnational research on income (as distinct from wage) inequality in developed countries, and research on income inequality in U.S. counties and states. The United States is an attractive choice for such case study, given that the inequality upswing here is one of the most spectacular among developed nations. Counties furthermore constitute a large set of welldescribed social microcosms that can be studied over time.

Finally, our purpose is in part descriptive. We want to derive some sense of the relative importance of the many mechanisms that may contribute to contemporary inequality trends as well as geographical variation in inequality. This task is made complex by the fact that variables that affect county-level inequality may operate at different levels, with sociodemographic factors operating at the level of the county and others, such as institutional and political factors, operating at the level of the state. Furthermore, the nature of the variation in inequality induced by various causal factors may differ: some factors, such as deindustrialization, are likely to affect inequality in a longitudinal fashion, while others are more likely to generate cross-sectional variation in inequality. To capture nested processes and the cross-sectional versus longitudinal modus operandi of causal factors, we adopt an analytical approach based on multilevel analysis. With this methodology we are able to distinguish county-level, statelevel, and longitudinal processes affecting income inequality within a county. We also calculate standardized estimates of the regression coefficients that permit assessment of the substantive significance of the various parameters.

In the next section we discuss issues associated with the use of counties in analyzing income inequality within the broader project of understanding inequality trends in contemporary society. We then draw on previous research to construct a model of family income inequality in U.S. counties. Later sections discuss data and methods and present the results of the analysis.

\section{USING COUNTIES AS UNITS OF ANALYSIS}

Counties as units of analysis present advantages as well as drawbacks for a study of income inequality (Nielsen and Alderson 1997). We begin with the advantages. First, counties represent social microcosms that differ considerably in level of development and social makeup-more so, in some respects, than advanced industrial countries differ among themselves - thereby providing rich variation in social context. Second, data collection, being performed by centralized agencies, is likely to be more 
uniform across counties than cross-national data is across nations. Third, counties are observed at multiple time-points and so naturally produce a time series of cross-sections, a powerful design for disentangling longitudinal and cross-sectional variation in inequality. Fourth, counties, as contrasted with metropolitan statistical areas, are properly nested within states, permitting a more straightforward assessment of how states' institutional and political contexts affect inequality across counties. A fifth, substantive advantage of the focus on within-county income inequality is that it provides clues to the mechanisms producing inequality at a relatively local level. Compared to inequality in the national labor force or in American society as a whole, inequality within a county is arguably more immediately perceptible by individuals, thus contributing more directly to their assessment of overall inequality (and of distributive justice) in the larger society. ${ }^{4}$ Finally, within-county income inequality is one component of national income inequality (although not the only one). Thus, understanding mechanisms producing inequality within a county contributes, in part, to an understanding of national inequality trends. This important point is further discussed below.

There are also limitations to the use of counties as units. First, states and counties, being subunits of a single national entity, are institutionally more homogeneous than a cross-national sample of independent nations. The role of institutional factors, which loom so prominently in crossnational comparative research, may be harder to discern across counties and states. Thus, one would not expect to find institutional effects as strong as those found in cross-national comparisons of advanced industrial countries (e.g., Kenworthy 2004). On the other hand, there are reasons (discussed below) to believe that such institutional factors do matter, so that variation across states in policy would be reflected in variation across states in within-county inequality.

Second, as mentioned earlier, within-county inequality is only one component of national inequality. As Firebaugh (2003) explicates, national income inequality can be decomposed into a weighted sum of withincounty inequality (arising from differences in the incomes of families within counties) and between-county inequality (arising from differences in the average incomes of counties). Thus, shedding light on mechanisms of within-county inequality illuminates only part of the process producing inequality at the national level, as the latter also incorporates inequality due to differences in average income across counties. The purpose of this

${ }^{4}$ That is, assessment of distributive justice in the United States by the working-class person in Peoria is likely more informed by the lifestyles of neighbors and members of the broader local community than it is by media accounts of the lifestyles of multibillionaires. 
American Journal of Sociology

study, however, is disentangling causal mechanisms generating inequality within counties, not estimating national income-inequality trends, which is better done by directly aggregating individual income data to the national level. Inequality, it should be stressed, is a property of a collectivity, not of individuals. What county data do allow us to do-and individual data and data aggregated at the national level do not-is to associate geographical variation in the socioeconomic and institutional context of the collectivity with variation in income inequality, providing insight into social mechanisms generating inequality.

A third limitation is that county boundaries cannot be assumed to correspond to meaningful social-system boundaries. This issue is important in evaluating effects of the political process, broadly defined. U.S. states have a degree of political autonomy and differ in their institutional arrangements in ways that can affect the income distribution to a greater extent than institutional differences between counties (Hanson 1999). Political and institutional processes affecting the distribution of income should operate primarily at the level of the state rather than the county (see Tomaskovic-Devey and Roscigno [1996] for an alternative view emphasizing county-level political processes). This is one primary reason for our use of a multilevel model, where we measure political and institutional variables at the level of the state rather than the county.

Fourth, another situation in which county boundaries do not coincide with system boundaries is when a county is embedded within a larger system of economic interactions. An example would be a residential county outside a central city, with a large proportion of the county population commuting to work downtown during the day. Another example would be that of an area of suburban development encroaching on a formerly rural county. The juxtaposition of wealthy suburbia with rural poverty would heighten within-county inequality in a statistical sense, even though these two social spheres may not in other respects constitute an integrated social system (and the observed inequality may not be socially salient to the same degree). One should not, however, exaggerate the methodological implications of these examples and others like them. For one reason, the variables we use are measured on the resident population of a county, not the people who are employed there. Quite literally, the measures capture people where they sleep, not where they work. Second, many of the characteristics of a county that might be thought to confound analysis of the social bases of inequality are measurable. For instance, our analysis would not be confused by the commuting pattern or the suburban-rural configuration of the hypothetical counties, as income inequality and the socioeconomic variables are measured on the same county residents, and their underlying social heterogeneity would be revealed by such variables as educational heterogeneity and sectoral distribution of the labor force. 
Third, the special situation of counties adjacent to a metropolitan area, and the corresponding commuting pattern, can be captured by classifying counties along the rural-urban continuum using a scale developed by rural sociologists that incorporates a measure of adjacency to urban concentrations (Beale 2004).

\section{MODELS OF INCOME INEQUALITY WITHIN COUNTIES}

In the following subsections we attempt to integrate the several literatures on wage and income inequality identified earlier by specifying how demographic and social processes, labor market pressures, and state institutional and political context affect family income inequality within counties. Relevant variables included in the analyses can be crudely but usefully categorized as pertaining to (1) economic development and labor market trends, (2) sociodemographic trends, and (3) aspects of the institutional and political context. We discuss these variables in turn in a substantive mode, postponing the details of sources and computations to a later section.

\section{Economic Development and Labor Market Trends}

Previous cross-national and cross-county research on income inequality has identified a number of trends associated with economic development that may affect the distribution of wages and thus, indirectly, the distribution of income. These include trends related to increasing productivity and economic prosperity, labor force shifts between industrial sectors, urbanization, and the spread of education (Kuznets 1955; Danziger and Plotnick 1986; Nielsen and Alderson 1997; Alderson and Nielsen 2002; Bradley et al. 2003; Moller et al. 2003). These trends are clearly interrelated. However, earlier research has developed theoretical expectations (or, perhaps, accumulated lore) concerning mechanisms by which these trends can independently, and in some cases nonmonotonically, affect economic inequality.

Before the onset of the Great U-turn, the conventional wisdom concerning the relationship of income inequality with economic development was embodied in the Kuznets curve, the inverted U-shaped trajectory of inequality over the course of economic development conjectured by Kuznets (1955). As advanced industrial societies during the course of the 20th century were located on the descending segment of the curve, the Kuznets pattern implied a negative relationship between inequality and economic development (Lindert and Williamson 1985). With the onset of the Uturn in the United States in the 1970s, it was tempting to conclude that 
American Journal of Sociology

the Kuznets pattern had been reversed, so that inequality was now increasing with development. Deeper scrutiny revealed that increasing inequality in the early phase of the upswing was in fact associated with stagnant average incomes and that much of the inequality upswing resulted from declining incomes within the lower regions of the distribution (Levy and Michel 1991). A reasonable interpretation of these findings was that the Kuznets regime was still in place in the United States, with economic development producing declining inequality, but that the economy was simply not growing. To assess these alternative hypotheses we measure economic development as county median family income, a variable similar to GDP per capita, which is used to measure development in cross-national research, and we add county median income squared to the model. The Kuznets pattern suggests that income inequality (as a linear term) will be negatively associated with county median income. Insofar as the Great U-turn represented a fundamental change in the relationship between income inequality and development, so that above a certain development threshold inequality begins to increase with development, one would expect that income inequality will be positively associated with county median income squared.

The impact of development on the distribution of the labor force among traditional and modern sectors of production is a principal mechanism in the scenario of evolution of income inequality proposed by Kuznets (1955; see also Nielsen 1994). One component of the modern sector is the secondary sector, or industry proper-the manufacturing of tangible goods. The secondary sector in advanced industrial societies has been characterized by a relatively low level of income inequality, owing in part to the strength of labor organization in that sector. Since the middle of the 20th century, employment in the secondary sector has declined in the United States and other advanced industrial societies-a trend labeled deindustrialization - with corresponding expansion of the tertiary (service) sector. These labor force trends are sometimes interpreted as heralding the emergence of a postindustrial society. Deindustrialization was exacerbated by the late 20th-century globalization trend in which relatively low-skilled manufacturing jobs were "exported" abroad to developing economies offering inexpensive labor (Bluestone and Harrison 1982; Tienda, Smith, and Ortiz 1987; Wilson 1987; Browne 2000). The contributing role of deindustrialization in the inequality upswing was suspected early on (Bluestone and Harrison 1982). The rationale is that deindustrialization forces a shift of employment from the relatively high-wage and egalitarian manufacturing sector to the more unequal tertiary sector, boosting the overall level of inequality. Inequality within the tertiary sector is relatively high because of the bifurcation of the sector into the very profitable, higher-wage producer services, including finance, insurance, 
and real estate, on the one hand, and other, more labor-intensive, lowerwage services, including personal services, on the other hand (Levy and Murname 1992; Lorence and Nelson 1993; Singelmann et al. 1993; Sassen 1998; Alderson 1999). In addition, producer service industries are information- and knowledge-intensive; these industries have created more managerial and professional jobs than the remaining service industries, increasing income heterogeneity within this component of services. Differentiation within the service sector accounts for much of the association between postindustrialization and earnings inequality (Lorence and Nelson 1993). We can predict the following associations between income inequality and the distribution of the resident labor force of a county among industry sectors. Controlling for other variables in the model, income inequality is expected to be (1) lower in counties with higher employment in manufacturing, (2) higher in counties with higher employment in high-wage service industries, and (3) higher in counties with higher employment in low-wage service industries.

Kuznets (1955) conjectured that urban centers in a developing economy would be characterized by both higher average incomes (due to the greater productivity of the modern industrial production system) and greater inequality (because of the greater diversity of occupations in the urban economy). Studies have produced mixed results regarding the association between urbanization and inequality (see, e.g., Farbman 1975; Danziger 1976; Long, Rasmussen, and Haworth 1977; Nielsen and Alderson 1997). Nord (1980) found in a study of cities that that the association between urbanization and inequality is curvilinear. Small cities have the highest inequality because small urban and rural areas that are detached from metropolitan economies lack employment opportunities. Medium-sized cities have the lowest inequality because of greater employment opportunities. The highest inequality is found in metropolitan areas. Scholars disagree on the interpretation of this finding. Some reason that large metropolitan areas should have higher inequality, independent of level of development and the industrial mix, because such areas represent agglomeration economies that are characterized by high productivity, particularly among skilled workers. This productive environment generates greater wage disparities between workers (Garofalo and Fogarty 1979; Nord 1982; Sassen 2001). In addition, larger, more densely populated counties have higher rents, which often translate into higher incomes (Nord 1980). Yet a more recent study suggests that inequality may be lower in large metropolitan areas because, compared to nonmetropolitan areas, they have lower poverty rates (Miller and Weber 2004). Furthermore, counties with persistently high poverty rates between 1960 and 2000 are largely rural. Indeed, counties are more likely to be persistently poor when they are smaller and when they are disconnected from urban 
American Journal of Sociology

areas. In light of the extant literature, we expect that income inequality is higher in more urbanized counties. However, given the mixed results reported in the literature, we would not be surprised if this hypothesis did not hold.

As mentioned earlier, county boundaries do not correspond to boundaries of local socioeconomic systems, so one must consider the position of a county relative to surrounding urban and rural areas. A county next to a metropolitan area would be, intuitively, more urbanized than one surrounded by a rural hinterland. One measure of urbanization we use is population density, but this measure does not capture effects of urbanization in surrounding counties. Thus we also use a more sophisticated measure of county-level urbanization developed by rural sociologists that classifies counties based in part on whether they are adjacent to other urbanized areas (Beale 2004). Since this Beale typology consists of a set of indicators, we can use it to test for any nonlinear effects such as those suggested by Nord (1980) and Alperovich (1995).

The claim that the spread of education plays an important role in reducing inequality stems from ancient roots (Mill 1848; Tinbergen 1975). The basis of the claim is that, holding demand constant, educational expansion should generate lower inequality because the supply of highly skilled workers should increase, thus depressing upper-level wages and lowering overall inequality (Lecaillon et al. 1984). Comparative studies of income inequality across countries that vary substantially in level of development show a strong negative association overall between inequality and the spread of education, particularly secondary education (e.g., Nielsen 1994; Nielsen and Alderson 1995). Based on this tradition one would predict that counties with higher levels of education will have lower inequality.

An alternative view holds that the relationship of income inequality with educational development is more complex than the simple supply and demand argument suggests. Researchers adopting this alternative perspective point out that, as educational systems expand to incorporate greater proportions of the population of a developing society, the relative sizes of educational strata (to simplify, the educated vs. the noneducated) change. Insofar as strata with more education command higher incomes, these income differentials between educational strata will generate a certain amount of inequality tracing an inverted $\mathrm{U}$-shaped trajectory as a function of educational expansion. This is a special case of sector dualism (Kuznets 1955; Lecaillon et al. 1984, pp. 86-90; Simpson 1990; Crenshaw and Ameen 1993). In fact, in some cross-national data sets one can detect a trend of increasing inequality with educational development over a short range at low levels of educational development (Nielsen 1994, p. 667). This focus on compositional effects of educational development on in- 
equality is echoed in a seemingly independent research tradition that views heterogeneity in the distribution of educational achievement as directly contributing to heterogeneity (i.e., inequality) in the distribution of income (Chiswick 1974; Jacobs 1985). Insofar as income levels are some monotonically increasing transformation of educational credentials, it follows that a highly heterogeneous distribution of educational credentials should give rise to a heterogeneous - that is, unequal-distribution of income. We will measure educational heterogeneity using an entropy-based measure described later (Theil 1972). From the perspective represented by Jacobs (1985) we predict that, keeping the average level of educational achievement of county population constant, greater heterogeneity in the distribution of educational achievements will be associated with higher income inequality.

\section{Sociodemographic Trends}

Cross-national and cross-county studies of household and family income inequality emphasize the importance of sociodemographic trends associated with racial distribution, age distribution, and family composition. The nature of race relations in the United States is one factor implicated in the remarkably high levels of income inequality in this country, as compared to other advanced industrial societies (Nielsen and Alderson 1997). A pattern of systematic income disadvantage of blacks relative to whites would tend to raise the level of income inequality in the United States, as compared to other societies less fractured along racial lines. To capture the potential income disadvantage of blacks at the county level we introduce the percentage of blacks in the population as a variable in the model for income inequality. ${ }^{5}$ Researchers have found that wage and income inequality are higher when the black population is larger (Blalock 1957 ), in part due to (1) differences in family structure across racial groups (Cancian and Reed 2001); ${ }^{6}$ (2) race-based wage inequality resulting from differences in human capital, variations in the industrial structure across areas, and discrimination (McCall 2001); and (3) relatively high unemployment among black householders, particularly young black males (Wilson 1987). Yet researchers have also found that even after these factors

\footnotetext{
${ }^{5}$ Nielsen and Alderson (1997) use a measure of race dualism calculated from the proportion of black families and the average incomes of black and nonblack families to capture the impact of race on overall inequality. We use a simpler measure, \%black, for consistency, as we cannot calculate a corresponding dualism measure for the Hispanic population. Black-white dualism and \%black are, however, highly correlated.

${ }^{6}$ In 2006, estimates from the Current Population Survey (CPS) indicate that less than one-quarter of white children lived in single-parent households, while over half of black children did (U.S. Bureau of the Census 2006).
} 
American Journal of Sociology

are controlled, a systematic income disadvantage of blacks persists. Thus we predict that, controlling for other variables, \%black will be positively associated with inequality. ${ }^{7}$

A more recent sociodemographic trend has been a rapid increase in the Hispanic population in many parts of the United States, largely through immigration. Rapid population growth, either through natural increase or migration, has been associated with greater income inequality, especially when growth inflates the proportion of the population with relatively low skills (e.g., Lindert and Williamson 1985; Borjas 1994; Nielsen 1994). Thus, we predict that the percentage of Hispanics in a county will be positively associated with inequality.

The age composition of the population may affect inequality in complex ways. Nielsen and Alderson (1997) found that the size of the elderly population had a significant positive effect on inequality in 1970, no significant effect in 1980, and a negative effect in 1990. This pattern was consistent with the scenario proposed by Levy and Michel (1991, p. 38) of an upward movement of elderly families in the income distribution during the 1970s and the 1980s as a result of the Social Security program's achieving its full impact on cohorts reaching retirement age during this period and of the indexing of Social Security benefits. We expect to find the same pattern of effects for the percentage of the population age 65 and over from 1970 to 1990 (\%aged) as Nielsen and Alderson (1997) did. Furthermore, we expect a continuation of the trend, with an even stronger negative effect of this variable in 2000 than in 1990.

A conspicuous social trend of the 20th century has been the massive influx of women into the labor force. Researchers have disagreed on the consequences of this trend for income inequality. Some scholars argue that income inequality has declined as women's labor force participation and earnings have increased because the share of families without this source of income has declined (Nielsen and Alderson 1997; Cancian and Reed 1999; Blau, Ferber, and Winkler 2006). Some women, particularly women in low-income families, have increased their full-time labor force participation because fathers no longer earn incomes sufficient to maintain a family. Thus, women's employment can help move low-income families toward the mean, thereby lowering inequality (Mincer 1962; Cohen and Bianchi 1999). Others argue that greater opportunities for women in the labor market have attracted the continued labor force participation of

\footnotetext{
${ }^{7}$ Any systematic income disadvantage of blacks is almost certainly related to processes of residential segregation (Massey and Denton 1988, 1998; Cohen 1998; Jacobs and Blair-Loy 2001; Massey 2001). However, we do not have a measure of race segregation at the county level, so we cast the hypothesis in terms of the proportion of blacks, even though segregation may well be a major mechanism underlying an association between \%black and income inequality.
} 
women after marriage even among high-income families (Cohen and Bianchi 1999; Blau et al. 2006). Indeed, between 1970 and 1995, the labor force participation rate of women has risen most dramatically for new mothers and highly educated mothers (Blau et al. 2006). This should contribute to inequality for a variety of reasons. First, assortative mating based on education and skills causes the incomes of spouses to be positively correlated, so that increased labor force participation by married women tends to increase the spread of incomes for married couples (Thurow 1987; see also Karoly and Burtless 1995; Burtless 1999). In addition, women's greater participation in the labor force can increase inequality if women are disproportionately relegated to lower-paying, part-time occupations, so that an influx of low-income women expands the bottom of the income distribution, producing greater inequality. Given earlier findings of a negative association between women's labor force participation and inequality using both county data and cross-national data, we expect to find this pattern again in this study; nevertheless, theoretical arguments to the contrary are compelling, so we would not be surprised by a finding in the other direction. To put it formally, our provisional (and tentative) expectation is that higher female labor force participation rates will be associated with less inequality.

Finally, the inequality upswing in the United States coincided with a substantial upswing in the proportion of families headed by a single woman (Levy and Michel 1991), a trend sometimes referred to as the "femininization of poverty" (e.g., Bane 1988; McLanahan, Sorenson, and Watson 1989). Indeed, Burtless (1999) estimates that $21 \%$ of the increase in overall family income inequality between 1979 and 1996 reflected changes in family structure. In addition, Nielsen and Alderson (1997) find a strong association at the county level between the proportion of households headed by women and family income inequality. Therefore, we predict that \%female-headed households will be positively associated with inequality.

\section{Institutional and Political Context}

Scholars engaged in cross-national research have increasingly emphasized the role of the institutional and political context in generating wage and income inequality. Wage and employment trends in the United States, as compared to most other OECD countries during the last decades of the 20th century, represent a puzzle. While the United States experienced "falling unemployment, falling to steady real wages, and rapidly rising wage inequality," the majority of EU countries experienced "rising unemployment, rising real wages, and comparatively stable relative-wage levels" (Blau and Kahn 2002, p. 5). Labor economists have developed a 


\title{
American Journal of Sociology
}

theoretical synthesis to understand that episode, termed the unified theory. The theory derives its "unified" status from the fact that it is an integrated explanation of the divergent employment, average wage, and wage inequality trends in the United States and other OECD countries. The gist of the theory is well summarized by Blau and Kahn $\left(2002\right.$, p. 5): ${ }^{8}$

\begin{abstract}
Since the early 1970s, there have been a variety of shocks to which labor markets in all countries have been exposed, including the slowdown in productivity growth dating from the early 1970s, the oil-price increases of the 1970s and early 1980s, the fall in the relative demand for unskilled labor since 1980, and disinflation in the 1980s and 1990s. . . . It has been hypothesized that the flexible U.S. labor market was able to accommodate these shocks by letting absolute and relative real wages adjust, allowing its unemployment rate to stay low. In contrast, in most other OECD countries, labor-market institutions kept overall real wages rising and prevented unskilled workers' relative wages from falling as fast as they did in the lessrestricted U.S. market (in some cases preventing any fall in low-skilled workers' relative pay), thus producing sharp increases in unemployment in these countries.
\end{abstract}

Thus, different outcomes in the United States and other OECD countries are viewed as a result of the same labor market trends' interaction with different institutional contexts. The greater flexibility of the U.S. institutional context, relative to other industrial countries, itself results from a number of factors. In the United States, compared to other countries, (1) collective bargaining plays a smaller role in wage determination, as indicated in part by the low rate of unionization, (2) unemploymentinsurance benefits, as well as related benefits such as vacation and sick leave, are less generous, (3) laying off or firing workers is easier and less costly for firms, and (4) the proportion of the labor force employed in the public sector is smaller (Blau and Kahn 2002).

The unified theory specifies a major role for the institutional context, emphasizing how wage-setting institutions, public employment, and welfare spending affect labor market flexibility. As it combines labor market considerations with attention to institutional factors, the theory appeals to many kinds of social scientists, from economists to political scientists to sociologists. Yet there are contradictory findings regarding the extent to which the political and institutional context affects labor market flexibility across countries (Blank 1994; Baker et al. 2004; Baccaro and Rei 2005; DiPrete 2005). One particularly relevant critique of the unified theory addresses its downplaying of the role of institutional change. While

\footnotetext{
${ }^{8}$ The term unified theory is attributed to Blank (1998). An essentially similar argument-with an emphasis on the role of North-South trade-was proposed earlier by Wood (1994, pp. 14-18).
} 
the unified theory recognizes the possibility of institutional change, it assumes that institutional arrangements are largely stable over time. However, research shows that institutions are dynamic and that institutional change helps explain variation in inequality across countries (Ebbinghaus and Kittel 2005; DiPrete et al. 2006). Furthermore, consistent with its roots in classical economics, the unified theory tends to underestimate the role that politics and idiosyncratic cultural factors, such as racial antagonisms, may play in rising income inequality in the United States (DiPrete 2005). We consider each of these criticisms by examining the impact of institutional change, including political changes, on inequality.

Most of the empirical research on the role of the institutional and political context has been conducted at the cross-national level, where institutional differences across units are most pronounced (Smeeding 1992; Kenworthy 1999; Levernier 1999; McManus and DiPrete 2000; Alderson and Nielsen 2002; Bradley et al. 2003; Brady 2003; Moller et al. 2003; Kenworthy and Pontusson 2005). In adapting some of the insights of the unified theory to the distribution of family income within U.S. counties, at least two important differences between the county setting and the cross-national one in which the unified theory was developed must be kept in mind. First, given its origins in labor economics, the unified theory emphasizes factors that determine the distribution of wages, as opposed to incomes. The distribution of household and family incomes, while affected by labor market processes, is also the result of demographic and social factors (such as \% female-headed households) that affect modes of aggregation of individuals into income-receiving units. As Kenworthy (2004, p. 93) explains,

\begin{abstract}
Since earnings typically are pooled within households, the distribution of earnings among households should be of greater concern to egalitarians than the distribution of earnings among employed individuals. The latter contributes to the former, of course, but if greater earnings inequality among employed individuals leads to rising earnings inequality among households, this can be offset by government redistribution. . . . Since other factors contribute to household earnings inequality-household size and structure, marital homogamy, as well as employment patterns-it might be wise to choose government tax and transfer programs rather than pay compression as the chief instrument for ensuring a reasonably low level of household income inequality.
\end{abstract}

Kenworthy's argument further suggests that the institutional and political context can affect the distribution of income among households and families through several pathways, with potentially opposite consequences. For example, the activities of a strong welfare state with centralized bargaining institutions might well succeed in compressing the 
American Journal of Sociology

distribution of earnings, at the cost of lowered labor market flexibility and higher unemployment (as labor economists might suppose). On the other hand, such strong welfare institutions might enable the state to alter inequality in the distribution of household and family incomes by means of redistributive tax and transfer policies, as a number of political sociologists would maintain (Kenworthy 1999, 2004; Bradley et al. 2003; Brady 2003; Kenworthy and Pontusson 2005).

Second, while we argue that the "action" of the political context and institutional structure in determining county income inequality takes place at the level of the state rather than the county, we recognize that variation in political and institutional factors among U.S. states is likely to be lower than that among sovereign nations. One implication of this difference is that tests of the effects of political and institutional factors on withincounty inequality are particularly stringent, since limited variation in the independent variables would tend to attenuate estimates of effects that are real but small. It follows that any significant effect of these factors across U.S. states represents potentially strong support for the existence of a relationship.

\section{Wage-Bargaining Institutions and Unemployment}

Wage-bargaining institutions are central to the scenario envisioned by the unified theory. Union activities are seen as affecting inequality by generating wage compression and helping maintain relatively high wages among workers (Freeman and Medoff 1984; Wallerstein 1999; Blau and Kahn 2002). Union strength may also result in states' developing more generous and more redistributive social policies because, in the United States as across the OECD, unions tend to be strong supporters of redistribution (Stephens 1979; Korpi 1989; Esping-Andersen 1990; Hicks and Misra 1993; Huber and Stephens 2001). Thus, in a cross-national perspective, nations with the strongest unions and wage-bargaining systems generally have the lowest levels of inequality (Bradley et al. 2003; Brady 2003). Observers generally agree that the United States differs from most OECD countries in having weak wage-bargaining institutions, including unions, allowing for lower average wages and greater wage dispersion. In comparing states within the United States, it follows that states with weaker unions should have more flexible labor markets and lessredistributive policies. Thus, we anticipate that states with lower levels of unionization should have higher inequality.

Unemployment, while not itself an institutional factor, corresponds to a major articulation of the unified theory, which views unemployment and inequality as alternative outcomes of the same strains on the labor market. According to this view, in a flexible labor market such as the 
United States the strains would result in lower wages and greater inequality; in less flexible settings, such the typical European country, they would produce unemployment (Wood 1994; Blau and Kahn 2002). ${ }^{9}$ Extending the unified theory to variations in income inequality among U.S. counties, one would have to argue that, controlling for exogenous trends in labor markets, unemployment and inequality represent alternative responses, so that unemployment and income inequality should be negatively related. This prediction from the unified theory is admittedly counterintuitive, as it goes counter to the positive unemployment-inequality association that many researchers might expect on more intuitive grounds (Gramlich and Laren 1984; Blank and Blinder 1986; Tobin 1994).

\section{State Institutional Context}

The state institutional context is important because it plays a primary role in the formation and expansion of social welfare policies and public employment, and because research has found that states are more redistributive when they have the capacity to pass and enforce social welfare policies (Orloff and Skocpol 1984; Skocpol 1985, 1992; Cauthen and Amenta 1996; Bradley et al. 2003). Thus, the state institutional context should be a predictor of inequality. We consider two dimensions of the institutional context. The first, public sector size, reflects both the capacity of states to alter inequality and the presence of a sector that is associated with a relatively egalitarian distribution of wages. According to both unified theory and comparative research on household and family income inequality, state capacity is an important dimension of the institutional structure. Indeed, states must be sufficiently large to alter inequality (Lee 2005). In addition, the public sector is less competitive, more highly regulated, and thus less likely to generate a highly unequal wage distribution than other industrial sectors (Kenworthy 2004; Lee 2005; Moller and Li, in press). Thus we expect that counties with higher employment in the public sector should have lower inequality. ${ }^{10}$

The second dimension, the extent of professionalization of the state legislature, is less prevalent in the literature on inequality (Fry and Winters

\footnotetext{
${ }^{9}$ Others have argued that the trade-off between inequality and unemployment is minimal (Kenworthy 2004).

${ }^{10}$ Fiscal capacity is an obvious prerequisite for policy development because states must have sufficient resources to respond to citizen demands for increased social spending and greater protection from market inequities (see Skocpol and Amenta 1986). Fiscal capacity, however, is heavily dependent on economic and industrial development (see Quadagno [1987] for a review). Thus, we exclude a direct measure of fiscal capacity from the analyses. We do, however, discuss the results of incorporating this variable in $\mathrm{n} .25$ below.
} 
American Journal of Sociology

1970; Soule and Zylan 1997; Leicht and Jenkins 1998). The 50 U.S. states have discrete legislative institutions that vary in their degree of professionalism. Service on the state legislature was once an amateur endeavor; service was part-time and compensation was minimal. By the mid-20th century service on the legislature had become a full-time, salaried occupation in many states. Professionalized legislatures may implement more redistributive social policies (Fry and Winters 1970). Fiorina (1994) argues that professionalism enhanced the power of the Democratic Party. Democratic politicians gained political control of state legislatures because their careers were more conducive to professionalism. Whereas Republican legislators often pursued private-sector careers, such as the practice of law, that prevented full-time legislative service, Democrats were more likely to pursue nonprofit or public sector careers that gave them more flexibility for, and greater rewards from, the professionalization of public office. Legislative professionalism may also encourage politicians to be more responsive to their constituencies, as reelection is more critical to their personal career pursuits (Maestas 2000). According to that view, we predict that states with more-professional legislatures will have lower inequality. ${ }^{11}$

\section{Political Context}

As DiPrete (2005) maintains, the political context and changes in this context are important, if not sufficiently studied, determinants of inequality. We propose that the 50 U.S. states vary in a number of dimensions of their political context, including political participation and party competition. In democratic societies voters elect candidates who they believe best represent their interests. Once elected, representatives face the ongoing pressure of their own future job security and hence tend to respond to citizen demands or face potential failure at future elections. If enfranchisement is necessary for poor citizens to influence the state and for the populace to express its interest in maintaining stable or rising wages (Hicks and Misra 1993; Soule and Zylan 1997), it follows that greater citizen participation in elections may generate more redistributive social policies (Skocpol and Amenta 1986; Cauthen and Amenta 1996; Amenta 1998). We use electoral turnout as a measure of citizen participation. We expect that states with greater citizen participation (electoral turnout) will generate more redistributive social policies, resulting in lower inequality.

${ }^{11}$ Other scholars have argued, conversely, that as legislatures have become more professional, the need to finance reelection campaigns limits their response to their constituents (Weber 1999; see also Maestas [2000] for a review). This leads to the opposite hypothesis, that states with more-professional legislatures will have higher inequality. 
Citizen participation is greater in states where politics are more competitive, in the sense that electoral support is more equally divided between parties. Furthermore, more politically competitive states offer greater citizen protection (Key 1949; Quadagno 1987). This has been particularly evident in the case of noncompetitive Southern states, where Democrats have historically dominated the state's executive and legislative branches. This pattern yielded governments that were less responsive to the needs of citizens, particularly the poor (Quadagno 1987; Weir, Orloff, and Skocpol 1988). Indeed, Jacobs (1982) found that more politically competitive states have lower inequality. Thus, another prediction is that inequality will be lower in counties located in more politically competitive states.

\section{State Policies}

The link between the state political and institutional context and inequality is primarily attributed to differences in state policies (Bradley et al. 2003; Moller 2003). In a cross-national comparative perspective, the U.S. welfare state is distinctive in that it largely consists of market-oriented policies designed to, first, encourage financial independence of households through gainful employment; second, promote support of needy households through private insurance and charitable organizations; and third, as a last resort, offer a safety net in the form of limited government assistance (Esping-Andersen 1990; Goodin et al. 1999). Within this general market-oriented approach, the 50 U.S. states vary considerably in their

welfare policies. The less-conservative states typically engage in greater social spending (including for education and public assistance) and more widespread social protection (Erikson, Wright, and McIver 1993). These states generally are more committed financially to public education and public welfare, and they have established more generous state minimum wages.

The public school system is one of the largest and oldest social programs in the United States, predating even public school systems in European countries (Page and Simmons 2000). Educational expansion, particularly at the secondary level, is associated with lower inequality in cross-national studies (e.g., Nielsen 1994). Insofar as public spending on education contributes to educational expansion, one would postulate a parallel association between public spending on education and lower inequality (Burtless 1996).

It is important to consider education spending because it is an indicator of educational opportunity that captures more than educational attainment. Indeed, spending is only moderately correlated $(r=.4)$ with graduation rates across states. Education spending should impact inequality 
American Journal of Sociology

because higher spending helps augment students' achievement, particularly among lower-SES students. Furthermore, students who study in schools with greater resources go on to pursue higher-paying jobs as adults (Burtless 1996; Page and Simmons 2000). Thus, spending taps into differences across states in the commitment of resources for providing educational opportunity and for subsidizing the development of human capital. We measure education spending as the percentage of total direct state and local government expenditures that is allocated to education. We predict that states spending more on education will have lower inequality.

The unified theory and cross-national studies of income inequality agree that spending on public welfare is also an important determinant of inequality (Blau and Kahn 2002; Bradley et al. 2003). Since the United States has a limited welfare state that offers a fairly modest "social wage," firms do not face severe pressures to meet high reservation wages in order to "compete" with public assistance. This allows for lower wages and wider inequality. However, states do vary notably with respect to welfare generosity. States with more redistributive policies should have less inequality. We measure welfare spending as the percentage of total direct state and local government expenditures that is allocated to public welfare. We predict that states spending more on welfare will have lower inequality.

The minimum wage has also been identified as a constraint on inequality, particularly by critics of the skill-biased technological change argument. While some scholars argue that increasing the minimum wage generates greater inequality through higher unemployment among the lowest-skilled workers (Stigler 1946; Meyer and Wise 1983), others argue that increasing the minimum wage is necessary to reduce family income inequality (Bluestone and Harrison 2001; see Volscho [2005] for a review). Indeed, some scholars contend that the declining real value of the minimum wage has generated wage dispersion at the lower tail of the income distribution, leading to higher family income inequality (Lee 1999; Card and DiNardo 2002; Autor et al. 2005; Volscho 2005). We predict that states with higher minimum wages will have lower inequality.

\section{DATA AND METHODS}

\section{County-Level Variables}

The dependent variable is inequality in the distribution of family incomes in each county, measured in 1970, 1980, 1990, and 2000. The data are gathered from published census materials from the 1970, 1980, 1990, and 
2000 censuses. Inequality is measured as the Gini coefficient using the formula

$$
R_{L}=p_{k-1}-\sum_{i=1}^{k-1} L_{i}\left(p_{i}\right)\left(p_{i+1}-p_{i-1}\right),
$$

where income categories are indexed from $i$ to $k, p_{i}$ is the cumulative population share, and $L_{i}$ is the cumulative income share for income category $i{ }^{12}$ The cumulative population share $p_{i}$ and income share $L_{i}$ are calculated from the raw income distributions (given as number of income recipients in each income category) by a Pareto-linear procedure explained by Nielsen and Alderson (1997, pp. 20-21). The Gini coefficient is expressed as a percentage, ranging from 0 to 100. A value of 100 corresponds to maximum inequality, with the entire income of a county received by a single family; a value of 0 corresponds to perfect equality, with the total income evenly distributed across families. ${ }^{13}$

Independent variables are listed with data sources in table 1. Median income is measured as median family income in constant 2000 dollars. We also report median income squared, which in the natural units has remarkably high values. Therefore, the values of median income are divided by 100,000 to permit the presentation of coefficients. Unemployment is measured as the percentage of the civilian labor force that is unemployed. Industry variables are measured as government sector size (the percentage of the labor force employed in public administration); manufacturing sector size (the percentage employed in the production of durable and nondurable goods); FIRE sector size (the percentage employed in finance, insurance, and real estate); and service sector size (the percentage employed in personal, entertainment, recreational, scientific, educational, and social services). Urbanization is measured through ruralurban continuum codes (RUCC) and population density. RUCC is a scaled variable that classifies all U.S. counties into nine categories based on size

\footnotetext{
${ }^{12}$ The Census Bureau does not publish detailed income data for families within counties due to strict confidentiality requirements, so it is not possible to adjust income for size of family, as can be done in some comparative income surveys of European countries (e.g., Bradley et al. 2003).

${ }^{13}$ We use family as opposed to household income because distribution data for household income are not available for counties in the 1970 census. Our findings should be similar regardless of the measure of income inequality used because the two measures are highly correlated. Using the CPS, we correlated the Gini coefficients for incomes of families and households at the national level from 1967 to 2004. Over time, the two coefficients are correlated at .997. In addition, using decennial census data, we compared the average Gini coefficients in 1979, 1989, and 1999 across states for households and families. We found that the two coefficients are correlated at .958. Finally, we compared Gini coefficients for household and family income across counties in 1999 and found that the coefficients are correlated at .927 .
} 


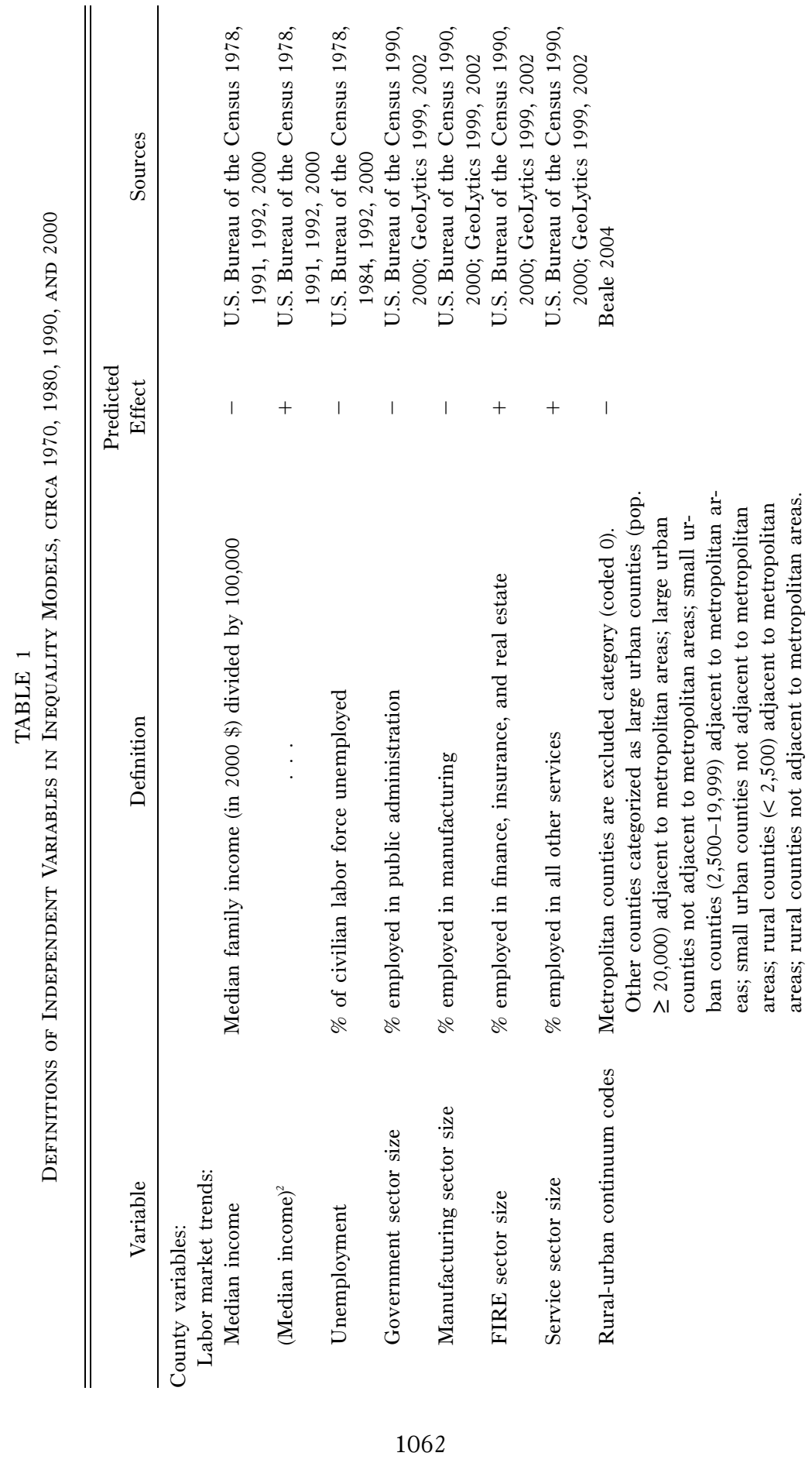



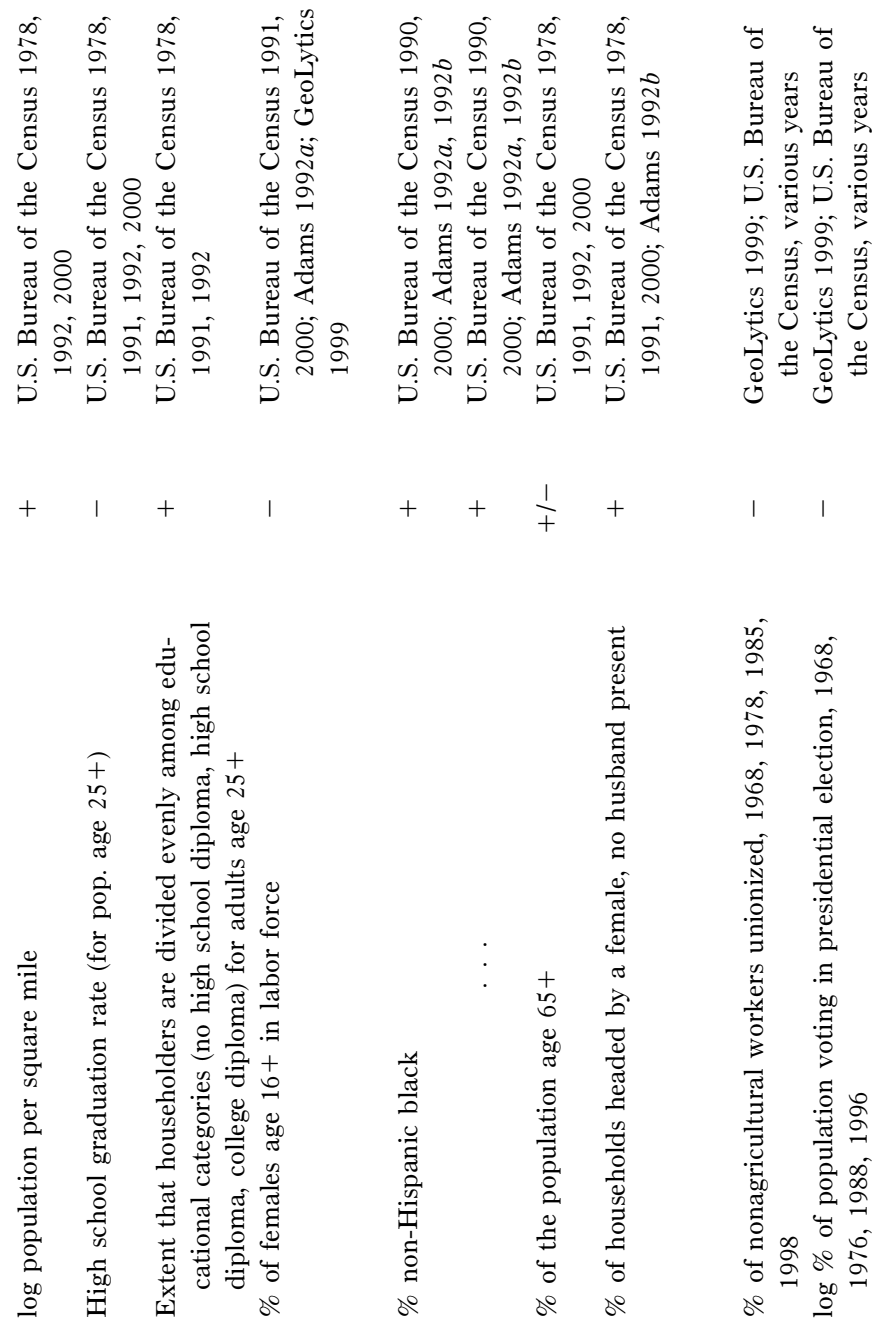

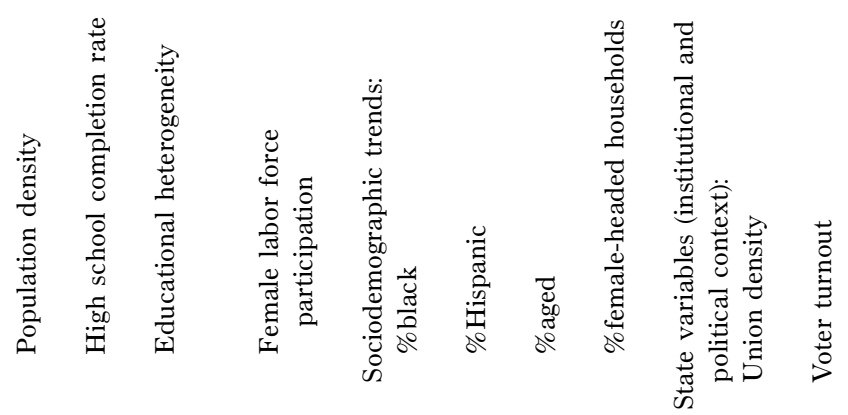

1063 


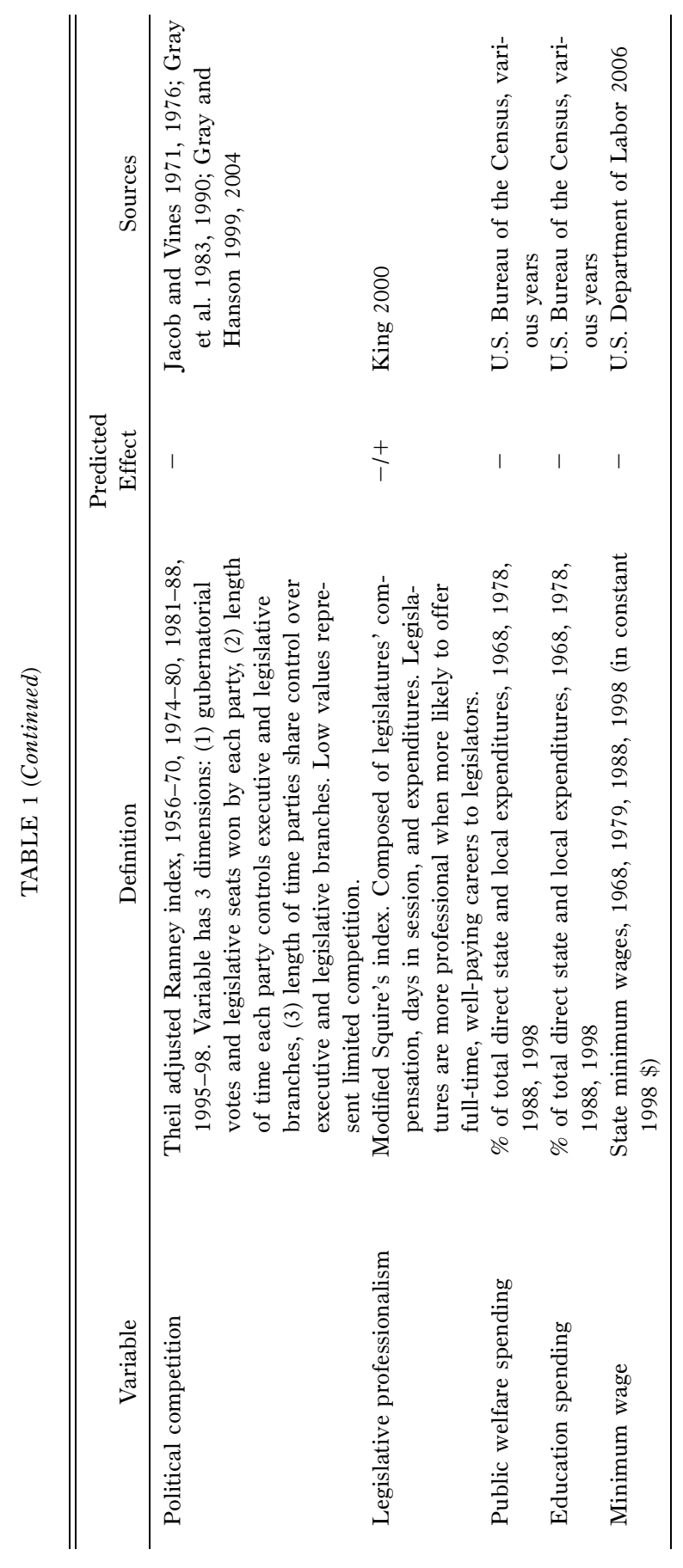


and proximity to metropolitan areas. We combine large metropolitan counties (population $\geq 1$ million), medium metropolitan counties $(250,000$ 1 million), and small metropolitan counties $(<250,000)$ into one category, used as the reference category. The six indicators included in the models correspond to large urban areas (population $\geq 20,000$ ) adjacent to metropolitan areas; large urban areas not adjacent to metropolitan areas; small urban areas $(2,500-19,999)$ adjacent to metropolitan areas; small urban areas not adjacent to metropolitan areas; rural counties $(<2,500)$ adjacent to metropolitan areas; and rural counties not adjacent to metropolitan areas (Ricketts, Johnson-Webb, and Taylor 1998). An adjacent county is one that is contiguous with at least one metropolitan area and has at least $2 \%$ of its labor force commuting to an adjacent metropolitan county. The Beale scale is the ordinal scale based on the RUCC codes (Beale 2004). The Beale scale is highly correlated over time (at .9 for 1970-80, .9 for 1980-90, and .8 for 1970-2000). Given the limited longitudinal variation, we include the Beale codes in the models at only one point in time, in 1970 , to capture cross-sectional variation in urbanization. Variation in urbanization over time is represented by change in population density, measured as the logged population per square mile.

The high school completion rate is calculated as the percentage of the population age 25 and older that graduated from high school. Following Nielsen and Alderson (1997), educational heterogeneity among adults age 25 and older is measured with Theil's $(1972$, p. 6) formula for entropy,

$$
H=\sum_{i=1}^{3} p_{i} \ln \left(\frac{1}{p_{i}}\right)
$$

where $i$ ranges from 1 to 3 , and $p_{i}$ is the proportion in each educational category (no high school diploma; high school diploma only; bachelor's degree or higher). The variable $H$ is a measure of how evenly adults are distributed among educational categories. An even distribution (i.e., onethird in each category) corresponds to a high value; a more skewed distribution corresponds to a lower value. Female labor force participation is measured as the percentage of females over age 16 in the labor force. Sociodemographic variables are measured as the percentages of the population that are black, Hispanic, and aged (65 and over) and the percentage of female-headed households with no husband present. ${ }^{14}$

\footnotetext{
${ }^{14}$ Migration is recognized as an important factor in the generation of inequality, both in a general historical context (Hatton and Williamson 1998) and in the contemporary United States (Borjas 1994). In the context of counties, migration raises several issues. The first concerns the presence of foreign immigrants. Our measure \%Hispanic captures this aspect, at least in part. The second issue concerns commuting migration between counties (e.g., in a metropolitan context). This aspect of migration is captured in the RUCC codes, which incorporate adjacency to a metropolitan area. Longer-term
} 
American Journal of Sociology

State-Level Data

The political variables are measured for the U.S. states. Union density is measured as the percentage of nonagricultural workers who are unionized, and voter turnout is calculated as the log of the percentage of the population that voted in the most recent presidential election. Political competition is measured as the index $R$, representing a transformation of the Ranney index. The Ranney index is based on three dimensions: (1) gubernatorial votes and legislative seats won by each party, (2) length of time each party controls the executive and legislative branches, and (3) length of time parties share control over the executive and legislative branches. The Ranney index measures Democratic Party control. A value of 0 reflects total Republican control, and 1 represents total Democratic control. A value of .5 represents evenly shared party control. We transformed the index via Theil's (1972) entropy formula to reflect the level of competition between the two parties:

$$
R=\sum_{i=1}^{2} p_{i} \ln \left(\frac{1}{p_{i}}\right)
$$

where $i$ ranges from 1 to $2, p_{1}$ is the value of the Ranney index, and $p_{2}$ is 1 minus that value. Low values represent limited competition, and high values reflect high competition (i.e., even shares of control by both parties). The index $R$ is gathered from secondary sources and is measured for the periods 1956-70, 1974-80, 1981-88, and 1995-98.

Legislative professionalism is measured with the modified Squire's index developed by King (2000, p. 329). This index ranges from 0 to 1 and includes, for both state legislatures, salary and living expenses, length of sessions, and service and operations expenditures per legislator. Education and public welfare spending are measured as percentages of total direct expenditures by state and local governments. Public welfare spending includes both institutional and noninstitutional assistance to needy families and the administrative cost for that assistance. Education spending includes elementary, secondary, and postsecondary state spending (excluding spending for university hospitals; U.S. Bureau of the Census 2001). Finally, CPI-adjusted minimum wage values are calculated for states that have minimum wages that are not solely targeted to a particular subset of the labor force (e.g., women). States without a minimum wage and

implications of intercounty migration affecting population growth or decline are captured by explicitly incorporating changes in population density over time into the models. Beyond this, we find it difficult to think of any mechanism through which intercounty migration might further affect inequality, perhaps through the labor supply or the distribution of skill, that is not already captured by these or other variables already in the models, such as unemployment, sectoral distribution of the labor force, educational heterogeneity, and high school completion rate. 
states with only targeted minimums are coded as 0 . We also include a dichotomous variable that identifies periods when states do not have a minimum wage policy (coded 1 when the minimum wage is 0 ).

\section{Multilevel Model}

We employ a multilevel method to disentangle the relative longitudinal (over time) and cross-sectional (either across counties or across states) impacts of variables on inequality. This is a useful feature of the method because research suggests that institutional variables (such as union density and decommodification of labor) tend to affect income inequality in cross-sectional fashion, so that the bulk of the variation is across countries, whereas other variables (such as globalization trends) affect inequality longitudinally, so that most of the variation is over time within countries (Alderson and Nielsen 2002). The multilevel methodology also permits incorporating into the same model in a principled way institutional and political variables measured at the state level together with economic and social variables measured at the county level.

Thus, we analyze variation in family income inequality with a multilevel repeated-measures model based on 3,098 counties observed at four time points (1970, 1980, 1990, and 2000); time is nested within counties, which are nested within states. The model adjusts errors to account for the interconnectivity of counties within states, and it permits any pattern of correlation over time.

The hierarchical model is composed of submodels at three levels, and most independent variables are measured at two levels with two indicators: the mean over time and the deviation from the mean. The level1 equation predicts counties' inequality over time. This equation includes deviations from the mean for county and state variables. The level-2 equation adds the means for the county-level independent variables, and the level-3 equation adds the means for the state-level variables (see table 1). The level-1 model is in the form

$$
\begin{aligned}
y_{t i j}= & \pi_{0 i j}+\pi_{1 i j} t 80_{t i j}+\pi_{2 i j} t 90_{t i j}+\pi_{3 i j} t 00_{t i j} \\
& +\pi_{m i j}\left(A_{m t i j}-\bar{A}_{m i j}\right)+\ldots+\pi_{n j}\left(E_{n t j}-\bar{E}_{n j}\right)+\varepsilon_{t i j},
\end{aligned}
$$

where inequality at time $t$ for county $i$ in state $j$ is predicted by an intercept $\pi_{0 i j}$, time-period effects $\pi_{1 i j}, \pi_{2 i j}$, and $\pi_{3 i j}$ (with 1970 as the excluded time period), coefficients $\left(\pi_{m i j}\right)$ for county mean-centered time-varying independent variables $\left(A_{m t i j}-\bar{A}_{m i j}\right)$, and coefficients $\left(\pi_{n i j}\right)$ for state mean-centered time-varying state-level independent variables $\left(E_{n t j}-\bar{E}_{n j}\right)$. Here, $A_{m t i j}$ represents county-level variable $A_{m}$ measured at time $t$ for county $i$ in state $j$, and $\bar{A}_{m i j}$ represents the mean of county-level variable $A_{m}$ for 


\section{American Journal of Sociology}

counties nested within states $(i j)$. Similarly, $E_{n t j}$ represents state-level variable $E_{n}$ measured at time $t$ for state $j$. These variables are deviated from the state means $(E)$ for all state variables $(n)$ in state $j$. Thus, the level-1 equation predicts inequality over time for counties within states. The level1 equation also includes an unstructured error term, $\varepsilon_{t i j}$, that permits any pattern of correlation over time. The covariance structure is blockdiagonal to account for different variance structures across counties (Littell et al. 1996; Raudenbush and Bryk 2002). The level-2 equation incorporates county means for the county-level time-varying economic and demographic variables entered in equation (1):

$$
\pi_{0 i j}=\beta_{00 j}+\beta_{0 m j} \bar{A}_{m i j},
$$

where $\pi_{0 i j}$ is the intercept from equation (1), $\beta_{00 j}$ is the average intercept across counties within states, and $\beta_{0 m j}$ represents the between-county effects for the county-level variables. Including deviations from county means in equation (1) and means in equation (2) permits a decomposition of total effects into between-period (longitudinal) effects and betweencounty (cross-sectional) effects (see Horney, Osgood, and Marshall 1995). This equation does not include an additional error term because the unstructured error variance in equation (1) accounts for clustering of time within counties.

The level-3 equation, however, includes a random effect to account for clustering within states:

$$
\beta_{00 j}=\gamma_{000}+\gamma_{00 n} \bar{E}_{n j}+\mu_{00 j},
$$

where $\beta_{00 j}$ is mean inequality across counties within states, $\gamma_{000}$ is the grand mean inequality across states, $\gamma_{00 n}$ represents the between-state effects, $\bar{E}_{n j}$ represents the means for the state-level variables, and $\mu_{00 j}$ is the state-level random effect.

Combining each of these equations yields the following reduced-form equation:

$$
\begin{aligned}
y_{t i j}= & \gamma_{000}+\pi_{1 i j} t 80_{t i j}+\pi_{2 i j} t 90_{t i j}+\pi_{3 i j} t 00_{t i j}+\pi_{m i j}\left(A_{m t i j}-\bar{A}_{m i j}\right) \\
& +\beta_{0 m j} \bar{A}_{m i j}+\pi_{n j}\left(E_{n t j}-\bar{E}_{n j}\right)+\gamma_{00 n} \bar{E}_{n j}+\varepsilon_{t i j}+\mu_{00 j} .
\end{aligned}
$$

The components of the reduced equation are described above. This equation illustrates that income inequality in time period $t$ in county $i$ in state $j$ is a function of a grand intercept, time period effects, county meancentered effects (i.e., deviations from the county mean over time), average county effects, state mean-centered effects (deviations from the state mean over time), and average state effects. Two error terms permit correlation 
between counties within states. ${ }^{15}$ They also permit any type of correlation over time within counties. ${ }^{16}$

\section{RESULTS}

Table 2 presents the overall means for all variables and average deviations from the means over time. The table reveals time trends that will be useful in interpreting regression results. Overall inequality ranged between a low of 36.8 in 1980 to a high of 38.4 in 2000. Median income increased by $\$ 8,322$ between 1970 and 2000 (from $\$ 35,106$ to $\$ 43,429$ in constant 2000 dollars). ${ }^{17}$ Unemployment increased between 1970 and 1980 but declined from 1980 to 2000. Employment in the manufacturing sector declined across the entire period, while the FIRE, service, and government sectors expanded. State-level variables exhibit a number of interesting trends. While $18 \%$ of workers were unionized on average over the period under study, rates of unionization declined steadily from $24 \%$ in 1970 to $11 \%$ in 2000. Public welfare spending, political competition, and legislative professionalism all rose monotonically over the period, while voter turnout and education spending, like unionization, declined monotonically.

\section{County-Level Economic Development and Labor Market Variables}

Table 3 presents the main regression results. Model 1 includes all the county-level development, labor market, and sociodemographic variables and three period indicators for 1980, 1990, and 2000. Model 2 includes all the state-level indicators of the institutional and political context and the period indicators. Model 3 combines these variables. To streamline

\footnotetext{
${ }^{15}$ We assume that values of the dependent variable for counties are correlated within states and thus adjust the error terms accordingly. It is also possible, however, that counties are correlated based on their proximity to other counties. We tested for the effect of a spatial correlation term (results not shown) and found that it does not improve the model fit or alter our key findings.

${ }^{16}$ In hierarchical modeling, restricted maximum likelihood (MLR) is generally preferred over full maximum likelihood (MLF) because MLF underestimates standard errors, generating liberal hypothesis tests (Raudenbush and Bryk 2002). MLR corrects for this bias. We therefore report coefficients based on MLR estimation. However, MLR estimation prevents a comparison of fit statistics across models. Therefore, we report fit statistics (AICC, BIC, and log likelihood) based on MLF estimation. The results presented in table 3 below are robust to the estimation method.

${ }^{17}$ The statistics for median income in table 2 are multiplied by 100,000 to assess dollar values.
} 
TABLE 2

Overall Variable Means and Deviations from the Mean by Period

\begin{tabular}{|c|c|c|c|c|c|}
\hline \multirow[b]{2}{*}{ VARIABLE } & \multirow{2}{*}{$\begin{array}{l}\text { Overall } \\
\text { MEAN }\end{array}$} & \multicolumn{4}{|c|}{$\begin{array}{c}\text { Average DEviation From } \\
\text { THE MEAN }\end{array}$} \\
\hline & & 1970 & 1980 & 1990 & 2000 \\
\hline \multicolumn{6}{|l|}{ County variables: } \\
\hline Inequality & 37.62 & -.28 & -.80 & .34 & .73 \\
\hline Median income & .39 & -.04 & .00 & .00 & .04 \\
\hline$(\text { Median income })^{2}$ & .16 & -.03 & .00 & .00 & .03 \\
\hline Unemployment .. & 5.91 & -1.40 & .87 & .68 & -.15 \\
\hline Government sector size $\ldots$. & 5.00 & -.11 & -.05 & -.18 & .34 \\
\hline Manufacturing sector size & 19.34 & 2.58 & 1.58 & -.76 & -3.41 \\
\hline FIRE sector size $\ldots \ldots \ldots \ldots \ldots \ldots \ldots$ & 3.93 & -1.01 & -.07 & .44 & .64 \\
\hline Service sector size $\ldots \ldots \ldots \ldots \ldots \ldots$ & 28.81 & -4.97 & -3.62 & .01 & 8.58 \\
\hline Large metropolitan .... & .06 & & & & \\
\hline Medium metropolitan & .09 & & & & \\
\hline Small metropolitan & .06 & & & & \\
\hline Large urban adjacent & .06 & & & & \\
\hline Small urban adjacent & .18 & & & & \\
\hline 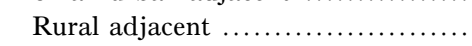 & .08 & & & & \\
\hline Large urban not adjacent & .05 & & & & \\
\hline Small urban not adjacent $\ldots \ldots \ldots \ldots$ & .23 & & & & \\
\hline Rural not adjacent $\ldots \ldots \ldots \ldots \ldots \ldots$ & .20 & & & & \\
\hline Population density $(\log )$. & & -.15 & .00 & .03 & .12 \\
\hline High school completion rate ........ & 54.63 & -17.30 & -6.83 & 1.43 & 22.70 \\
\hline Educational heterogeneity $\ldots \ldots \ldots \ldots$ & .90 & -.04 & .03 & .02 & .00 \\
\hline Female labor force participation .... & 47.01 & -10.35 & -2.33 & 4.89 & 7.79 \\
\hline \%black & 8.70 & .29 & -.22 & -.18 & .12 \\
\hline$\%$ Hispanic & 4.35 & -1.20 & -.60 & -.02 & 1.82 \\
\hline$\%$ aged & 13.74 & -1.80 & -.49 & 1.21 & 1.08 \\
\hline \%female-headed households .......... & 10.69 & -1.67 & -.18 & 2.08 & -.23 \\
\hline \multicolumn{6}{|l|}{ State variables: } \\
\hline Union density $\ldots \ldots \ldots$ & 17.82 & 6.24 & 2.32 & -2.10 & -6.46 \\
\hline Voter turnout $\ldots . . . .$. & 4.02 & .12 & .02 & -.07 & -.08 \\
\hline Political competition ........ & .61 & -.03 & -.02 & .01 & .04 \\
\hline Legislative professionalism .......... & .23 & -.07 & .02 & .02 & .03 \\
\hline Public welfare spending $\ldots \ldots \ldots \ldots$ & 11.40 & -3.08 & -.51 & -.25 & 3.83 \\
\hline Education spending $\ldots \ldots \ldots \ldots \ldots$ & 38.18 & 3.82 & .58 & -1.71 & -2.69 \\
\hline Minimum wage ..... & 3.86 & -.25 & .39 & -.37 & .23 \\
\hline
\end{tabular}

Note. $-N=3,098$ counties and 48 states. Empty cells indicate that the measurement is not applicable. 


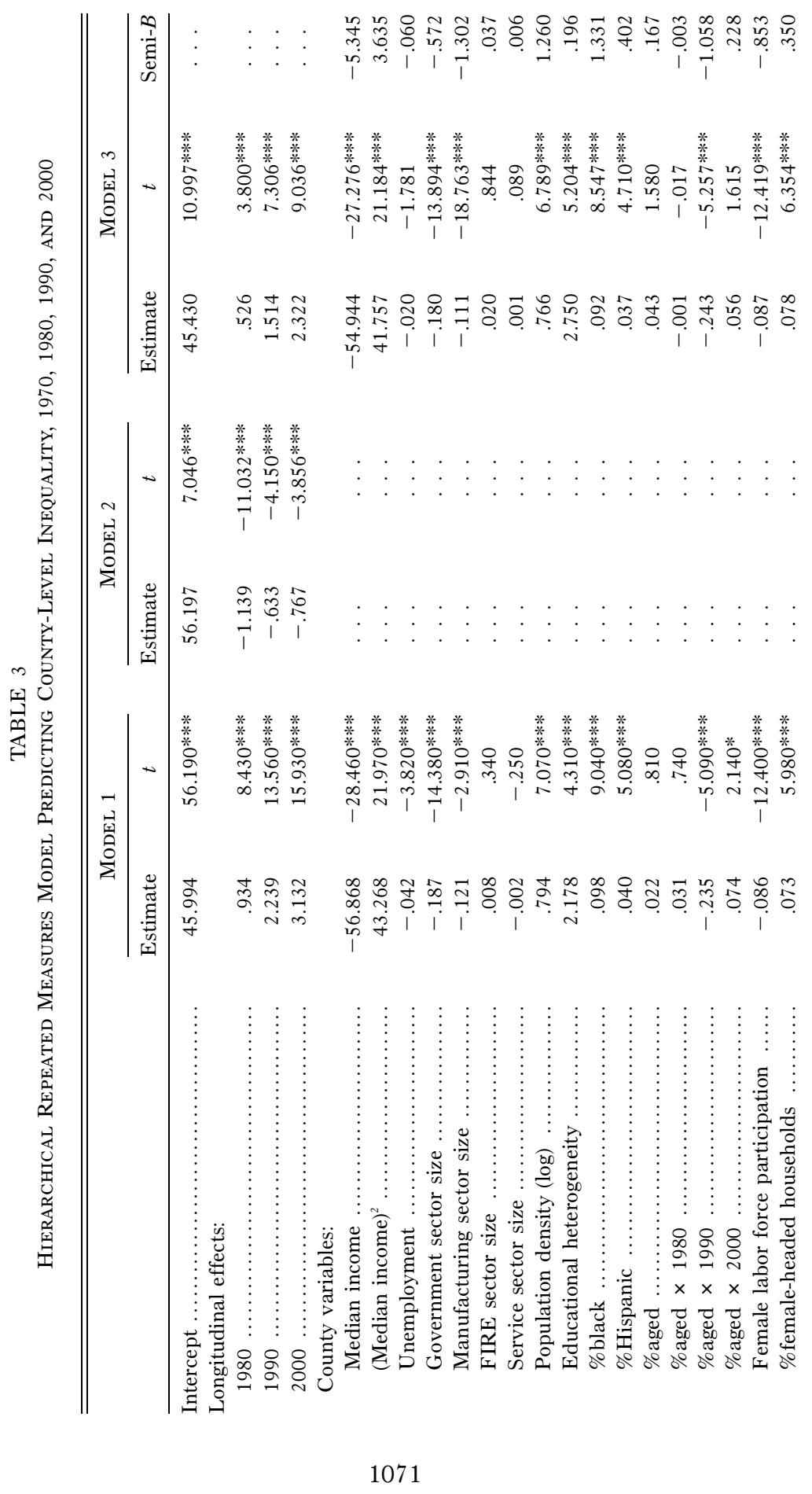




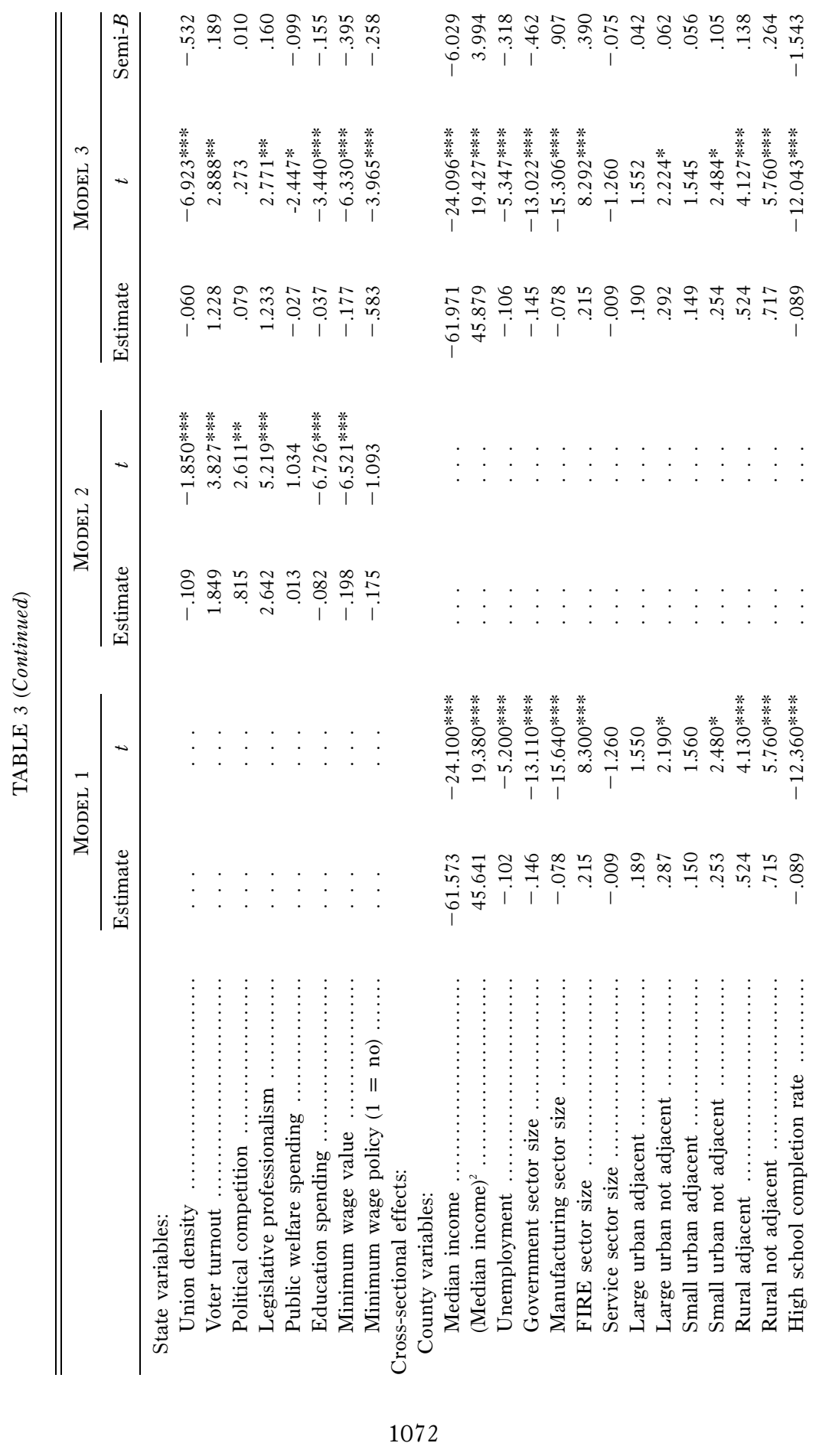




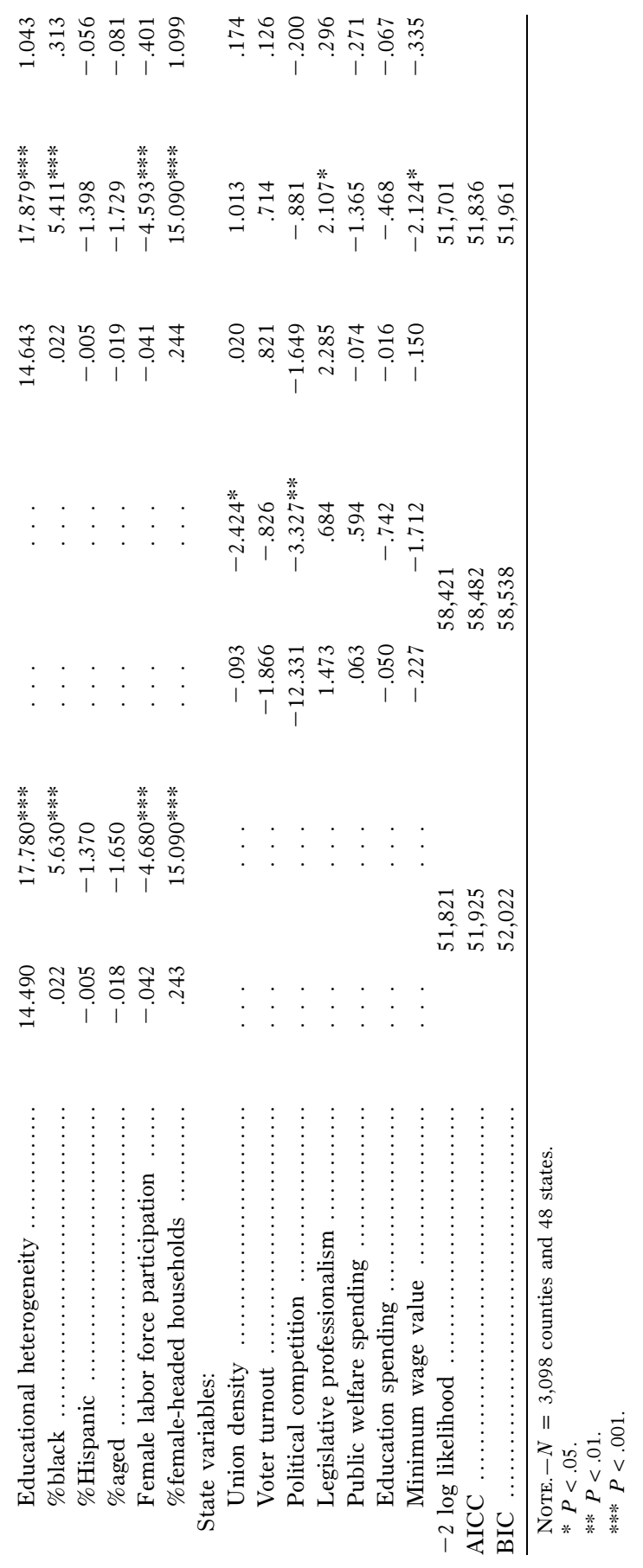

1073 


\section{American Journal of Sociology}

the discussion of results we focus on the full model (model 3), referring to the simpler models only as necessary. ${ }^{18}$

In model 3, the period effects for 1980, 1990, and 2000 increase in size, corresponding to the historical upswing in income inequality over the 1970-2000 period. Compared to the 1970 baseline, and controlling for other variables in the model, inequality was .5 points higher in $1980,1.5$ points higher in 1990, and 2.3 points higher in 2000. These significant period effects suggest that the full model does not completely account for the upward trend in inequality in the last decades of the 20th century.

Most of the remaining variables in the regression model have two effects. The longitudinal effects reflect the impact of deviations over time from the county means (or state means, in the case of state-level variables). They represent the effects of change in the independent variables over time. The cross-sectional effects represent the impact of overall (uncentered) county (or state) means. They correspond to the effects of geographical variation (across counties or states) in the independent variables. Median income, for instance, is found to have a negative effect on inequality that is highly significant both longitudinally $(-54.9 ; P<.001)$ and cross-sectionally $(-62.0 ; P<.001)$. Thus, rising median income in a county is associated with declining inequality (the longitudinal effect), and counties with higher median income at a given time point have lower inequality (the cross-sectional effect). However, the positive effects for median income squared both between periods $(41.8 ; P<.001)$ and between counties $(45.9 ; P<.001)$ indicate that, beyond a given level of development, inequality tends to rise with median income.

From a substantive point of view, median income is taken to be a generalized indicator of economic development. The pattern of coefficients of median income and median income squared indicates a curvilinear relationship of income inequality with economic development, so that inequality at first declines with economic development (a trajectory consistent with the downward movement of the Kuznets curve in advanced industrial societies) and later starts increasing with economic development (the U-turn). The results in model 3 of table 3 show that this relationship of inequality with development persists even though a number of variables that are associated with this curvilinear pattern are explicitly measured and included in the model (e.g., manufacturing sector size as a measure of deindustrialization and \%female-headed households). This suggests

\footnotetext{
${ }^{18}$ In separate analyses (not shown) we ran an unconditional random-effects model to partition the percentages of variation attributable to time periods, counties, and states. We found variance components of $5.27,5.77$, and 4.74 for the residual, counties, and states, respectively. Thus, $33 \%$ of the variation in income inequality is over time, $37 \%$ of the variation is between counties, and $30 \%$ of the variation is between states.
} 
that the mechanisms underlying the U-turn are not entirely accounted for by our full model and that the residual trend is captured "descriptively" by the combination of median income and median income squared in the model. The results further indicate that the curvilinearity of the inequalitydevelopment relationship emerges cross-sectionally as well as longitudinally.

To help portray the relationship between inequality and economic development, figure 3 maps the county median income averaged from 1970 to 2000. Figure 3 illustrates that median income is substantially higher in the Great Lakes region, in pockets of the West, along the California coast, and in the Northeast. Longitudinal and cross-sectional zero-order correlations are presented in appendix table A1.

A principal articulation of the emerging unified theory discussed earlier is that wage inequality is higher in the United States than in other OECD countries in part because weaker institutional constraints allow real wages in the United States to decline for important segments of the workforce and unemployment to remain low. By contrast, other OECD countries have experienced stable or rising real wages at the cost of rising unemployment. Projecting this trade-off of inequality for employment onto U.S. counties, the unified theory would imply the initially counterintuitive prediction that unemployment should be negatively related to inequality. We find that, longitudinally, the coefficient of unemployment is indeed negative, although not significant at conventional levels. Cross-sectionally, however, the coefficient is both negative and highly significant: overall, counties with higher unemployment also have lower inequality, a pattern consistent with the counterintuitive conjecture of the unified theory. We note, however, that the cross-sectional zero-order correlation between unemployment and inequality is positive (.29; see app. table A1) and that unemployment is not significantly associated with inequality when demographic variables are excluded from the model. Thus, the negative effect is conditional on the controls, although it does not result from excessive collinearity. ${ }^{19}$

Results for government sector size are consistent with expectations. Both longitudinally and cross-sectionally, increased employment in public administration is associated with lower inequality. Also, as expected from

\footnotetext{
${ }^{19}$ For instance, when \%female-headed households is excluded from the model, unemployment is nonsignificant. We interpret the sensitivity of the results to our control for female-headed households as indicating that, once we control for the fact that counties with a large population of single mothers have higher inequality (in part because single mothers are more likely to be unemployed), the residual influence of unemployment is negative and significant. We assessed collinearity using an ordinary least squares regression and found the level of collinearity involving unemployment acceptable according to a common rule of thumb (VIF $<10)$.
} 


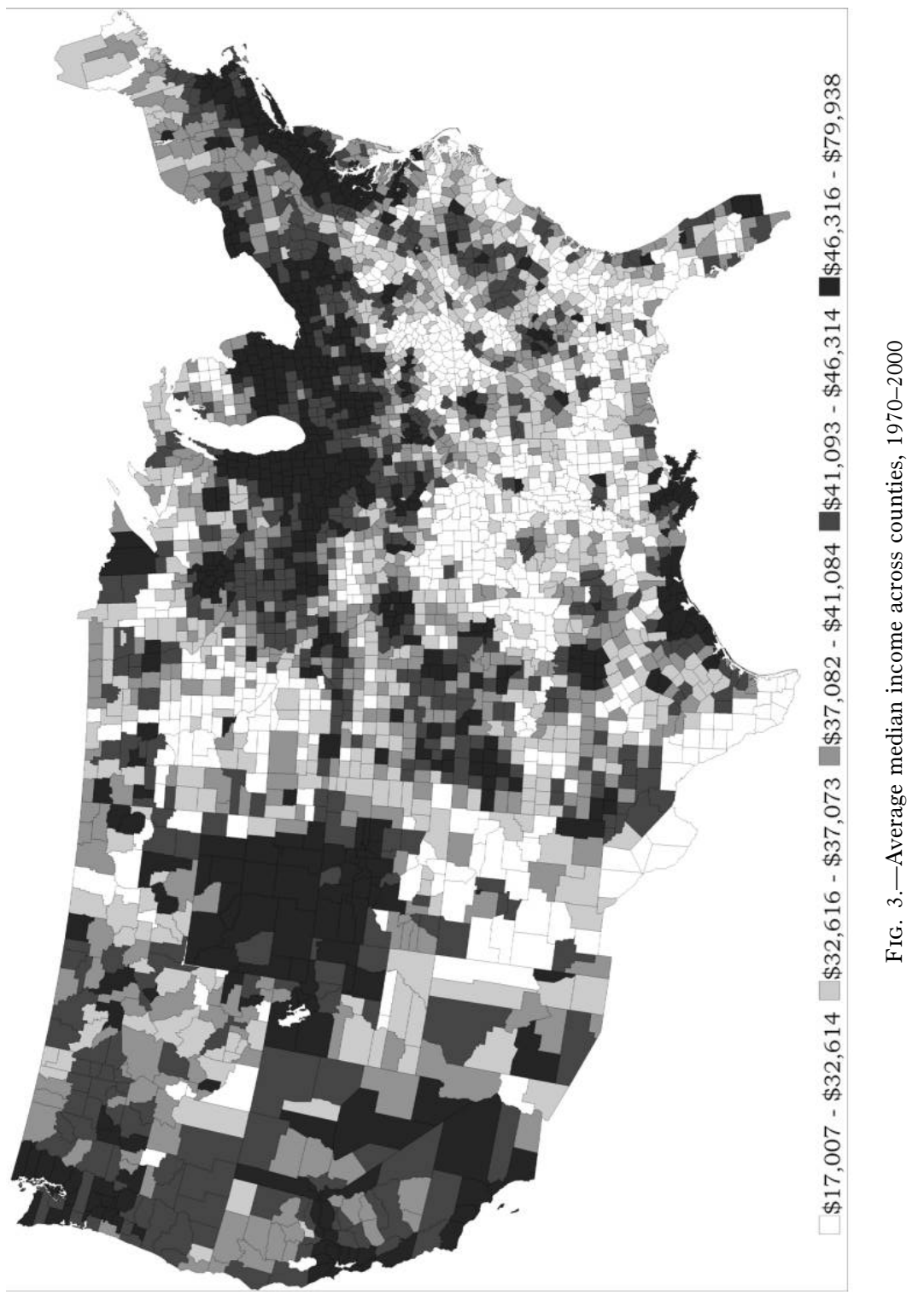


a sizable literature, deindustrialization (negatively measured as employment in manufacturing) results in higher inequality both over time and across counties, as manifested in the significant negative coefficients for manufacturing sector size. The manufacturing sector has declined over time for the United States as a whole (see table 2), a pattern of deindustrialization that has been viewed as partly responsible for the overall increase in inequality over the period considered (Harrison and Bluestone 1988). Figure 4 maps average levels of employment in manufacturing across counties. During the period under study, manufacturing employment is greatest, on average, in the Southeast and the Midwest.

In contrast, employment in FIRE industries is greatest in the West, the Northeast, and Florida. ${ }^{20}$ These counties have significantly higher inequality, on average, as is illustrated by the highly significant, positive cross-sectional effect of FIRE employment on inequality in table 3. Thus, net of manufacturing sector size, counties with a more pronounced knowledge-intensive postindustrial labor force profile have higher inequality. We should point out that the cross-sectional correlation between inequality and FIRE sector size is negative. However, once we control for median income (results not shown), the association becomes positive. Thus, controlling for the fact that counties with large FIRE industries have relatively high median income and that median income is negatively associated with inequality, we find that the coefficient for FIRE sector size is positive. This pattern suggests that the transition to a postindustrial economy has led to higher inequality. Theoretically, this should reflect the polarization of incomes found within this sector. While companies in FIRE industries pay remarkably high wages to some employees (augmenting median income), their lowest-wage workers, although a smaller segment of the sector, receive remarkably low incomes. Longitudinally, by contrast, growth of FIRE employment, while correctly signed, is not significantly related to inequality in this model.

Employment in the service sector (excluding FIRE industries) is nonsignificant both longitudinally and cross-sectionally. Interestingly, when we exclude controls for demographics, the longitudinal effect of service sector employment on inequality is significantly negative (results not shown). Turning to the correlation matrix (app. table A1), we see that counties with greater growth in the service sector also have greater growth in women's labor force participation (longitudinal correlation $=.74$ ). Thus, zero-order associations suggest that growth in the service sector is associated with lower inequality (independent of median income) because this sector disproportionately employs women. However, this effect does not persist in more fully specified models.

${ }^{20} \mathrm{~A}$ map showing this is available from the authors upon request. 


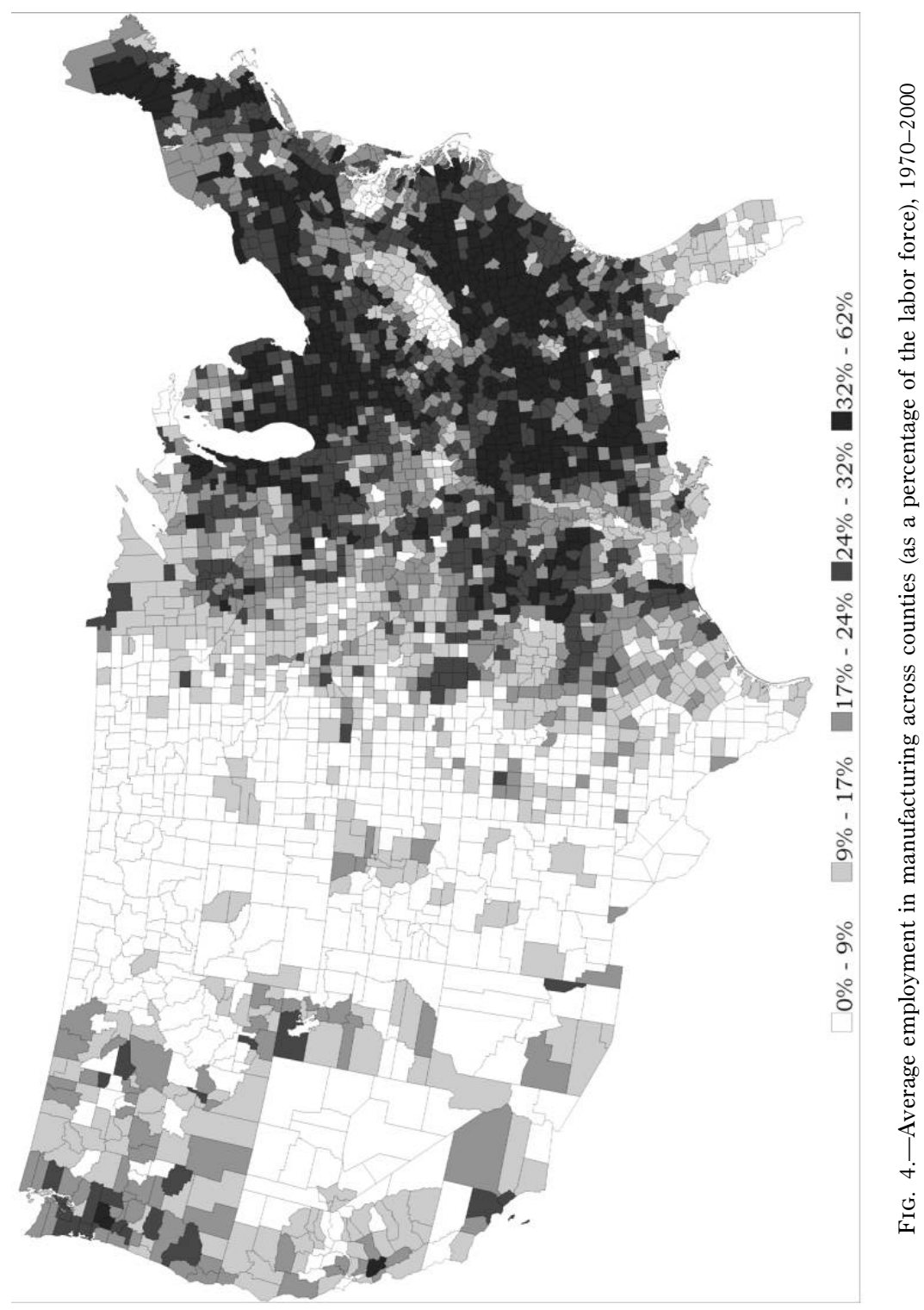


The extant studies on the association between urbanization and inequality produce contradictory results (e.g., Nord 1980; Miller and Weber 2004). Our results for urbanization reflect this chaotic literature. Figure 5 maps the degree of urbanization of counties, measured according to a modified Beale scale designed to reflect the clustering of counties into labor markets. ${ }^{21}$ Zero-order cross-sectional associations (app. table A1) are weak, barely suggesting that metropolitan counties (the darkest areas in fig. 5) and urban counties adjacent to metropolitan areas have relatively low inequality unconditionally. Rural counties and urban counties that are disconnected from metropolitan counties (the lightest shades in fig. 5) have relatively high inequality. This pattern corresponds with Miller and Weber's (2004) study of poverty. Once we control for all the variables comprised in the full model, however, the only significant effects correspond to rural adjacent and rural not adjacent counties. These effects are positive, implying that, controlling for other variables in the model, inequality is higher for the most rural counties. ${ }^{22}$ This is consistent with the findings of Miller and Weber (2004), contra Nord (1980). This pattern of results illustrates why the literature has not reached a consensus on the association between urbanization and inequality. The association is clearly not linear, and it is dependent on the proximity of nonmetropolitan counties to metropolitan counties.

The Beale categories, representing the relatively unchanging geographical situation of counties, are unsuitable for capturing the longitudinal effect of urbanization on inequality. To evaluate this effect, model 3 in table 3 also includes a longitudinal measure of population density. (Population density is not included cross-sectionally as it is highly collinear with the Beale indicators.) As the geographical setting-including county area-is fixed, this variable essentially captures the effect of population growth on inequality. The positive longitudinal effect for population density is consistent with theoretical expectations, rooted in Kuznets's (1955) classic conjecture that urbanization generates rising inequality owing to the greater heterogeneity of the urban economy relative to the rural. This

\footnotetext{
${ }^{21}$ The original Beale scale orders counties, by descending degree of urbanization, as metropolitan, large urban adjacent, large urban not adjacent, medium urban adjacent, medium urban not adjacent, rural adjacent, and rural not adjacent; this ordering is somewhat controversial as it does not reflect labor market patterns (Ricketts et al. 1998). In the regression analyses we enter these codes as dichotomous indicators, rather than as a single scaled variable. In drawing the map in fig. 5, we have created an ordinal scale by reordering the categories to better reflect labor market areas as metropolitan, large urban adjacent, small urban adjacent, rural adjacent, large urban not adjacent, small urban not adjacent, and rural not adjacent.

${ }^{22}$ Note also that large urban counties that are not adjacent to metropolitan counties have significantly higher inequality in table 3 , in spite of a minimal zero-order correlation (.01) in app. table $\mathrm{A} 1$.
} 


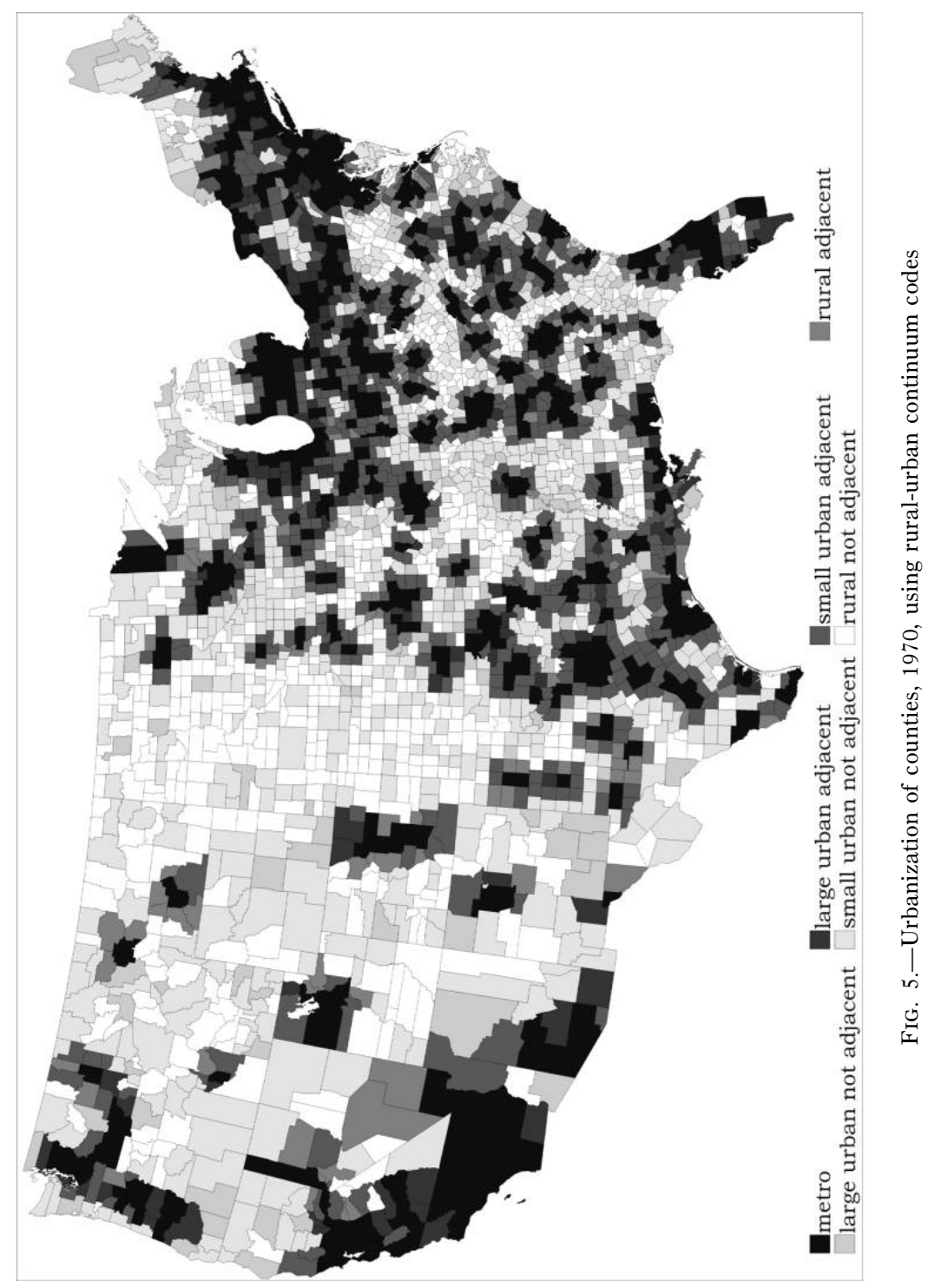


finding may also reflect disequilibrium conditions that result in areas with rapid population growth (Long et al. 1977; Nord 1982).

We capture the distribution of education in a county with two variables: high school completion rate (cross-sectionally only) and educational heterogeneity (both longitudinally and cross-sectionally). We omit the longitudinal component of high school completion because of high collinearity. ${ }^{23}$ The cross-sectional high school completion effect continues to capture unique differences between counties. Cross-sectionally, high school completion has a highly significant negative effect on inequality: counties with more educated populations have lower inequality. Educational heterogeneity is included in the model both longitudinally and crosssectionally. Zero-order correlations between educational heterogeneity and inequality are negative but very small (app. table A1). However, once we control for the curvilinear association between levels of development and inequality, the effect becomes positive and highly significant. This positive effect is robust to other measures of economic development and demographics. This finding is consistent with the argument that the distribution of educational attainment affects the distribution of income as a function of the dispersion of education, independent of the wage-enhancing effects of educational expansion (Jacobs 1985; Nielsen and Alderson 1997).

Systematic differences in income between racial/ethnic groups in the United States represent a source of inequality that could elevate overall inequality above the level found in other advanced industrial countries. We capture the racial/ethnic composition with two variables-\%black and \%Hispanic. As expected, counties with a larger black population have higher inequality. This effect is positive and significant both longitudinally and cross-sectionally. By contrast, the size of the Hispanic population affects inequality longitudinally but not cross-sectionally. The longitudinal effect is positive, indicating that counties where the Hispanic population has grown over the period under consideration have also experienced increased inequality. The absence of a cross-sectional effect of \%Hispanic suggests that the county average over the entire period may not capture well the more recent trends of Hispanic migration. The positive effects on inequality are attributable, in part, to substantial differences in average incomes between blacks and Hispanics, on one hand, and the rest of the population, on the other. In addition, as income inequality is higher within the black and Hispanic populations of the United States than within the

${ }^{23}$ High school completion, reflecting development, has very little independent longitudinal variance when other steadily increasing aspects of development (e.g., median income, population density, and service sector employment) are included in the model. High school completion is also highly correlated longitudinally (above .8) with service employment, female labor force participation, and public welfare spending, and including it in the models produces unacceptably high variance inflation factors. 
American Journal of Sociology

white population (U.S. Census Bureau 1998), these positive effects may also capture a direct compositional effect.

We hypothesized that the effect of \%aged (i.e., the percentage of the population over age 65) will shift over time in a fashion that reflects the historical upward movement of the aged population toward the middle of the distribution of income as a result of the increasing impact of the Social Security program (Levy and Michel 1991; Nielsen and Alderson 1997). Thus, \%aged should affect inequality positively in earlier cohorts (as the elderly were then inflating the bottom of the income distribution) and negatively (or less positively) in later ones, as the elderly are now receiving incomes closer to the overall average through full benefits under the Social Security program and the indexing of benefits. To permit comparisons of the effects of \%aged at different time points, model 3 of table 3 incorporates \%aged together with interactions of this variable with the 1980, 1990, and 2000 indicators. While signed in a fashion consistent with our expectations, the longitudinal effect of \%aged is nonsignificant. As this coefficient corresponds to the effect of \%aged in 1970 (the reference period), it means that at that time a large elderly population was not associated with greater inequality. The coefficient corresponding to the interaction of \%aged with 1980 is negative and nonsignificant, and the interaction with 1990 is larger, negative, and highly significant $(P<.001)$, indicating that in 1990 a large elderly population was associated with substantially lower inequality in a county. However, by 2000, the coefficient is nonsignificant and positive. Viewed together, these results provide only partial support for the scenario of a consistent inequality-moderating movement of the elderly population in the income distribution over time, originally postulated by Levy and Michel (1991; see also Nielsen and Alderson 1997).

Female labor force participation has a consistent negative effect on family income inequality that is significant both longitudinally and crosssectionally. This suggests that, the fact of women's lower average wages and the phenomenon of assortative mating notwithstanding, the net impact of the increase in labor force participation by women is to create more families with incomes closer to the center of the distribution, thus lowering inequality. This is consistent with the argument of Cancian and Reed (1999) and the findings of Nielsen and Alderson (1997), contra Thurow (1987).

The last sociodemographic variable is \%female-headed households, a factor that has been suspected as a major culprit in the U.S. inequality upswing. Insofar as female-headed households have below-average incomes, an increase in the proportion of female-headed households should inflate the bottom tail of the distribution of family incomes and contribute to rising inequality. The results lend support to this hypothesis: both 
longitudinally and cross-sectionally, counties with greater proportions of female-headed households have higher inequality.

\section{State-Level Institutional and Political Context}

Model 2 in table 3 estimates the effects of state-level institutional and political characteristics separately. Model 3 includes these, controlling for economic and sociodemographic variables. We discuss the effects in model 3. With the state-level variables, the longitudinal effects reflect the impacts of time-specific deviations of variables from their state means. The crosssectional effects represent the impacts of overall state-specific means.

We find that union density has a significant, negative effect on inequality longitudinally, but the cross-sectional effect is nonsignificant. ${ }^{24}$ This suggests that net of policy, labor market (including manufacturing employment), and demographic variables, decline in union membership has been associated with greater inequality. However, controlling for the other variables, states with a tradition of strong unions do not differ significantly with respect to inequality from states with no such tradition. These findings lend partial support to the widespread view that unions compress and stabilize wages. As unions have weakened, incomes have indeed become more unequally distributed.

Voter turnout has a significant positive effect longitudinally and is nonsignificant cross-sectionally. Thus, states in which political competition has increased are also those in which within-county inequality has increased. While we hesitate to speculate at length about this unexpected result, we note that the positive effect of voter turnout obviously runs counter to many commonplace assumptions regarding the effects of mass participation on government policy and the distributional consequences of such policy. As touched on above, the scholarly literature often implies that the citizenry holds policy preferences that are redistributive in either intent or effect and, thus, that redistributive policy is a likely consequence of high levels of citizen participation. Such accounts, however, tend to overlook the fact that mass policy preferences are, when measured, not particularly redistributive in the United States, especially when compared to policy preferences in other advanced industrial societies (Brooks and Manza 2007). We speculate, therefore, that our results for voter turnout reflect the fact that, ceteris paribus, the "median voter" in the United

\footnotetext{
${ }^{24}$ The cross-sectional effect of union density is also negative and significant $(P<.05)$ in model 2 , but this effect disappears when economic and sociodemographic factors are controlled for.
} 


\section{American Journal of Sociology}

States may not be as strongly oriented toward redistributive policy as is often assumed. ${ }^{25}$

Political competition is nonsignificant both longitudinally and crosssectionally, while legislative professionalism has positive effects on inequality in both dimensions. ${ }^{26}$ These results are consistent with the argument that professionalism reduces the responsiveness of legislators to constituents. However, they starkly contradict the idea that professionalism results in a more redistributive policy (Fry and Winters 1970), either inherently or because it favors Democratic Party dominance (Fiorina 1994). ${ }^{27}$

The four remaining variables are characteristics of state policy. Public welfare spending, education spending, and minimum wage value have negative longitudinal effects on income inequality. The effect of public welfare spending is moderately significant $(P<.05)$ and the effects of both education spending and minimum wage value are highly significant $(P<$ .001). Thus, states in which these policy ingredients have grown over the period have also been characterized by declining within-county inequality. However, these variables are not strong predictors of inequality between states. While the cross-sectional effect of minimum wage value is moderately significant $(P<.05)$ in the expected negative direction, cross-sectional effects of public welfare spending and education spending do not reach significance. The final measure of state policy, an indicator of the absence of a state minimum wage policy, is included only longitudinally (between periods) in the model. This variable is included because some states have never had a minimum wage policy and others didn't imple-

\footnotetext{
${ }^{25}$ Another potentially important aspect of the state institutional structure is fiscal capacity. Based on the observation that fiscal capacity is often a prerequisite for the effective implementation of redistributive policy, we added longitudinal and crosssectional effects for revenue per capita to model 3 of table 3 . Revenue is not a significant determinant of inequality, and it does not enhance the model fit.

${ }^{26}$ Note that political competition is significant in model 2 of table 3 . However, once we control for variation in the demographic composition of counties, political competition does not alter levels of inequality longitudinally or cross-sectionally.

${ }^{27}$ The external organization of states might also impact inequality. This includes processes of interstate competition for investments and pressures toward policy conformity (Powell and DiMaggio 1991; Soule and Zylan 1997; Leicht and Jenkins 1998). States face direct and indirect pressures toward policy conformity through networks and membership in common social categories, such as region of the country (Soule and Zylan 1997). We examined this perspective by including a measure of total social welfare spending per capita in adjacent states (results not shown). The findings in model 3 of table 3 are robust to this control. We do not include this variable in model 3 because of high cross-sectional collinearity (VIF $=13$ ). In additional analyses (not shown), we also introduced an indicator variable coding for Southern states. This variable did not significantly affect inequality and does not improve the fit of model 3 , and other results are robust to this control.
} 
ment such policies until the mid-1970s. This longitudinal effect is again negative, as expected on theoretical grounds, and strongly significant ( $P$ $<.001)$.

To summarize the overall pattern of results for state-level variables, including policy variables, we find some strong longitudinal effects, but not exclusively in the theoretically expected direction. Cross-sectional effects, however, are more modest. These mixed findings may not be especially surprising. Note again that we are testing for effects of social spending at the state level. As suggested earlier, the context of U.S. states provides for a rather conservative test of institutional hypotheses. Within the "liberal" context of a federal welfare state providing for a comparatively low social wage, we do not expect that variation in welfare effort at the state level has overall distributional consequences commensurate with those of social policy variation along a conservative to social democratic continuum across continental European national contexts (EspingAndersen 1990). ${ }^{28}$ Although states' spending on public welfare and education may not vary enough cross-sectionally to significantly affect inequality, we do find that changes in spending over time are negatively associated with changes in inequality over time. Given that public welfare spending has increased over time, while education spending has declined (both measured as percentages of total direct expenditures), we can conclude that public welfare spending has had a net moderating effect on inequality while the trend in education spending has had a net inequalityenhancing effect over the 1970-2000 period (see table 2). ${ }^{29}$

\section{DISCUSSION}

Our empirical analysis investigates a number of potential causes of income inequality within counties, drawing from diverse literatures. We find that a number of variables are associated with inequality, either longitudinally, cross-sectionally, or both. At this point, we want to take stock of the

\footnotetext{
${ }^{28}$ Note also that the measures of welfare generosity we use do not take into account the value of programs administered exclusively by the federal government, such as the earned income tax credit, which, most analysts agree, does have significant ameliorative effects on family income inequality.

${ }^{29}$ The effect for public welfare spending only becomes significant once we include controls for labor market variables. In separate analyses (not shown) we found that public welfare spending becomes nonsignificant when we exclude the industrial mix variables or both development variables (median income and median income squared). Thus, once we consider that inequality has increased in counties experiencing deindustrialization and that these counties are located in states that have concomitantly increased welfare spending, welfare spending has had a net effect of lowering inequality.
} 
American Journal of Sociology

results and identify the factors that have been most important in the recent inequality upswing in the United States. To do this, we have calculated semistandardized regression coefficients (hereafter semi- $B$ ) that express the effect of a variable as the increase in Gini percentage points associated with an increase of one (overall) standard deviation in the independent variable. ${ }^{30}$ The semi- $B$ coefficients (presented in the last column of table 3) allow us to compare the relative magnitude of effects corresponding to independent variables with different metrics. It is important to note that in the unconditional regression model, we find that $33 \%$ of the variation in inequality is longitudinal, $37 \%$ is cross-sectional between counties, and $30 \%$ is cross-sectional between states. In this section we review some of the principal findings of the analysis that help explain these variations in inequality.

Institutional context and state policy.-A principal motivation of this study was to investigate the role in the generation of within-county inequality of the institutional and policy factors that have emerged so prominently in cross-national studies, in view of contradictory allegations concerning the role of these factors in the context of the United States (Kenworthy 1999; Bradley et al. 2003; Autor et al. 2005; Huber et al. 2006). In the present context, these variables are measured at the state level.

At the state level, we test a range of hypotheses relating the political and institutional context to the inequality experience of U.S. counties. Under the umbrella of a market-oriented, liberal federal welfare state, the 50 U.S. states vary in their welfare policies and, more generally, in their political institutions. The range of such variation, however, is considerably more constrained than what one observes cross-nationally. For this reason we see our test of such hypotheses as especially stringent and view a number of our positive findings as especially compelling. First, union density has a negative effect on inequality between periods. Thus, a one-standard-deviation decline in union density over time has increased inequality by .5 points. Second, we contribute to the long-standing debate regarding the link between minimum wages and inequality. We find that the size of the minimum wage is negatively related to inequality longitudinally and cross-sectionally, as is the presence of minimum wage law longitudinally.

Third, we find that legislative professionalism is positively associated with inequality. The degree of professionalism of state legislatures has varied measurably over time, with states moving from an amateur, part-

\footnotetext{
${ }^{30}$ Semi- $B$ is calculated by multiplying the unstandardized regression coefficient by the overall (pooled) standard deviation of the independent variable, calculated with all counties (or states) and periods combined.
} 
time legislator model to converge on a highly professionalized, full-time, salaried legislator model. While some have suggested that professionalism might be negatively related to inequality - as the emphasis on legislative careers might encourage greater responsiveness to constituents and favor the more redistributive party (Democrats) —our results are consistent with another strain in the literature that links professionalism to reduced responsiveness to constituents: we find that as legislative professionalism has increased, so has income inequality. Fourth, it is often suggested that the relatively small public sector in the United States helps explain why inequality here is high relative to other OECD countries. We test this directly by including, at the county level, a measure of the size of the government sector (as the percentage of the labor force employed in public administration). As expected, this variable has a highly significant, moderate negative effect on inequality both between periods and between counties. Fifth, and related, cross-national scholars of income inequality suggest that states' policies help to redistribute income across families; the United States is exceptional in its limited support of redistributive policies. We find that changes in public welfare and education spending are associated with changes over time in inequality, but as expected, this effect is relatively small, due to the nature of the American welfare state.

The bottom line is that we do find moderate effects of some of these variables on within-county inequality. Contrary to cross-national studies, where institutional and policy differences are manifested mainly between countries, we find that the effects of these variables are more apparent longitudinally. While these effects are not, as a group, as large as those of other factors we discuss below, we would conclude, to paraphrase a well-known expression, that policy matters . . . some.

In this context, we should point out a limitation of the present research, which is that family incomes, on which the inequality measure is based, are measured after transfers but before taxes. There are reasons to believe that much of the impact of policy that is redistributive is effected through taxes, in addition to transfers. Cross-national research on OECD countries has found that inequality of incomes before taxes and transfers does not vary greatly across nations. Variation in inequality is much greater when income is measured after taxes and transfers, with northern European countries then exhibiting much less inequality than English-speaking industrial countries. Likewise, while pretax and pretransfer inequality has generally risen in European countries following the economic shocks identified by the unified theory, posttax and posttransfer inequality has not risen to the same degree, suggesting that policies and programs affecting transfers and taxes have helped offset the rise in inequality. These patterns suggest that policy explains most of the variation in inequality across industrial countries (Bradley et al. 2003; Kenworthy 2004). 
American Journal of Sociology

The fact that within-county inequality is measured from the pretax (but posttransfer) income data available from the census may attenuate the impact of state policy differences on income inequality. We propose that a valuable direction for further research would be to go back to the individual income data and estimate posttax and posttransfer withincounty inequality. This is in principle feasible, and our research team is in fact planning to do it. While we may expect to find larger effects of state institutional and policy variables on inequality, we would not expect to find effects commensurate with those found in cross-national research, for two reasons. First, the fiscal power of states in the United States, and thus the potential impact of policy variation across states, is clearly more modest than that of independent nations. Second, in contrast with crossnational patterns, the institutional and policy effects we do find are more longitudinal than cross-sectional, suggesting a smaller role for durable institutional or ideological differences across states. ${ }^{31}$

While we find significant and substantively nonnegligible effects of institutional and policy variables, other variables have larger effects on inequality within counties. We summarize some of these results, in roughly descending order of their impact on inequality as measured by the semistandardized coefficients (table 3).

Inequality and economic development.-The strongest effects in the regression model, both longitudinally and cross-sectionally, correspond to median income and median income squared. We interpret median income, like GDP per capita in cross-national studies, as a generalized measure of economic development. The negative coefficient of the linear term and the positive coefficient of the squared term imply a $U$-shaped trajectory of inequality with development: with economic development in a county, inequality at first declines (corresponding to the descending segment of the Kuznets curve), and then the relationship turns up so that at high levels of development, further development is associated with increasing inequality. This is, of course, the famous U-turn that has characterized inequality in the United States, and some other advanced industrialized countries, in the last decades of the 20th century. Thus the U-turn persists even though the regression model controls for many variables that potentially capture the mechanisms that underlie this historical trend. If we had been entirely successful in explaining the inequality upturn, the relationship of inequality with development would have vanished, as the mechanisms producing inequality are explicitly included in the model.

${ }^{31}$ It is important to note that, given that dependent and independent variables are time varying and measured concurrently, we are unable to trace out the precise mechanisms through which independent variables affect inequality, either directly or indirectly through other variables in the model. 
The fact that the polynomial of development remains the strongest signal in the model reminds us that we have explained only a part of the process. The polynomial relationship itself is in a sense purely descriptive and begs the question of underlying causes.

Education.-Second in importance is a cluster of effects related to the spread of education. Counties with higher levels of education, measured as high school completion, tend to be less unequal than counties with lower levels, a pattern consistent with many cross-national studies (e.g., Nielsen 1994). However, educational heterogeneity has a moderate positive longitudinal effect on inequality. Thus, educational development may affect within-county inequality in two distinct and contradictory ways.

Labor force changes. - Shifts in the labor force between sectors have powerful effects on inequality. Manufacturing sector size as a proportion of the labor force has the expected negative effects, both longitudinally and cross-sectionally. So does the size of the government sector. Employment in FIRE industries has a substantial positive effect cross-sectionally. The other sectoral division of the labor force-namely, services properhas more tenuous effects. The effects of the manufacturing sector are substantially stronger than the effects of the other sectors, particularly over time. A possible interpretation of this pattern is that the distributional consequences of job shifts in the course of deindustrialization are largely attributable to the contraction of manufacturing employment rather than the growth of services.

Race and ethnicity.-Next in importance are variables measuring the racial and ethnic composition of the county. The strong longitudinal effect of the relative size of the black population indicates that counties where the black population has increased have also become more unequal. The size of the Hispanic population has a smaller longitudinal effect and no cross-sectional one. These findings suggest that the nature of race and ethnic relations-a factor that tends to be overlooked in the cross-national context-contributes substantially to income inequality in the United States.

Urbanization.-The effects of urbanization on inequality are complex. Longitudinally, counties urbanizing more quickly (as measured by population density) have greater inequality. Cross-sectionally, it is the most rural counties (as measured by the Beale classification) that have higher levels of inequality, but this effect is quite small.

Changing status of women.-In approximately sixth position in order of magnitude are effects related to the two measures of the changing role of women in the late 20th century. Both \%female-headed households and female labor force participation have substantial semistandardized effects, in positive and negative directions, respectively, and both longitudinally and cross-sectionally. It must be viewed as one contribution of studies of 
American Journal of Sociology

income (as opposed to wage) inequality like the present one that such sociodemographic effects can be captured in such a clear fashion.

Age composition.-We find that the only substantive impact of the proportion of the population that is elderly is in reducing income inequality in the year 1990. While this result is consistent with a scenario of historical change in the effects of this variable as the elderly population moves up in the income distribution, the effect does not persist in 2000. Overall this finding is not as clearly supportive of the scenario as the results of Nielsen and Alderson (1997).

\section{CONCLUSIONS}

Since the early 1970s, inequality in the distribution of family income in the United States has been on the rise. By 2000, it had reached a level comparable to that last experienced in the late 1920s. Other advanced industrial countries have likewise experienced upturns in inequality of varying severity in the last few decades (Freeman and Katz 1995; Hatton and Williamson 1998; Alderson and Nielsen 2002; Alderson, Beckfield, and Nielsen 2005). A wide variety of factors have been proposed as causes of the rise in inequality. U.S.-centered, cross-county studies identify economic development and demographic characteristics as the primary determinants of family income inequality. Cross-national studies of family and household income inequality also implicate economic development and demographic dimensions of inequality, but they stress as well the importance of political and institutional arrangements in the redistribution of income. U.S.-centered labor economists have implicated technological shifts and the wage premium offered to highly educated and skilled workers. In contrast, cross-national studies of wage inequality tend to focus on economic development and institutional factors, while overlooking the importance of demography. Theoretically sophisticated research on crossnational wage inequality has now accumulated to the point that scholars are hinting at a unified theory that would simultaneously account for trends in wage inequality and unemployment across developed countries (Wood 1994; Blank 1998; Blau and Kahn 2002; DiPrete et al. 2006). Inspired by the puzzle posed by the labor market experience of the United States relative to many other OECD countries, the unified theory explains recent wage inequality trends as the outcome of similar labor market trends' interacting with different institutional contexts.

Using data on the distribution of family income in 3,098 U.S. counties in 1970, 1980, 1990, and 2000, our research makes a number of contributions to the literature on income inequality. First, we integrate concepts from the cross-national and cross-county literatures by exploring how the 
state-level institutional and political context mediates the effects of labor market and sociodemographic variables on the distribution of family income. Second, we extend studies of cross-national income inequality to the study of the distribution of family and household income by incorporating a range of demographic and social factors that affect the aggregation of individuals into income-receiving units, in addition to labor market processes. We learn that labor market trends and political and institutional context are indeed important predictors of inequality. Third, our use of a multilevel repeated-measures model allows us to comment on the precise nature of the variation in inequality induced by labor market, sociodemographic, and institutional and political factors. With this method, we disentangle the relative longitudinal (over time) and crosssectional (across counties and across states) effects of such variables. Finally, we examine in detail one of the more famous (or infamous) U-turns on inequality and shed light on the nature of the forces driving rising inequality in a case that has regularly been presented as an exemplarpositive or negative — of the postindustrial future (Esping-Andersen 1999).

By incorporating the literatures on cross-county family income inequality with cross-national wage and income inequality, we have established that economic development, demographic, and political-institutional variables are important determinants of county-level family income inequality. Over time, the largest effects on inequality are measures of economic development, including counties' population density, manufacturing sector size, and median income. This suggests that rising inequality in the United States reflects in particular the growth of large, deindustrialized urban areas. Other important effects on inequality over time are the size of the black population, the size of the government sector, women's labor force participation, and union density. Thus, during periods when public employment is expansive, inequality is relatively low. Furthermore, as women have entered the labor force, they have effectively lowered family income inequality. But as unions have lost strength over time and as counties have become more racially heterogeneous, inequality has increased. Together, these findings suggest that changes in inequality over time are explained primarily by socioeconomic variables, but institutional variables also play an important, yet weaker, role. Between counties, we find that economic development-most notably the high school completion rate-and demographic variables have the largest effects on inequality. This suggests that inequality is lower in industrialized counties with more-educated populations, fewer female-headed families, and higher median income. The institutional context is not as important across counties, although inequality is lower in counties with a generous minimum wage. Our results, then, suggest that patterns in income inequality within and across U.S. counties are the result of labor market and demographic trends operating within changing institutional contexts. 


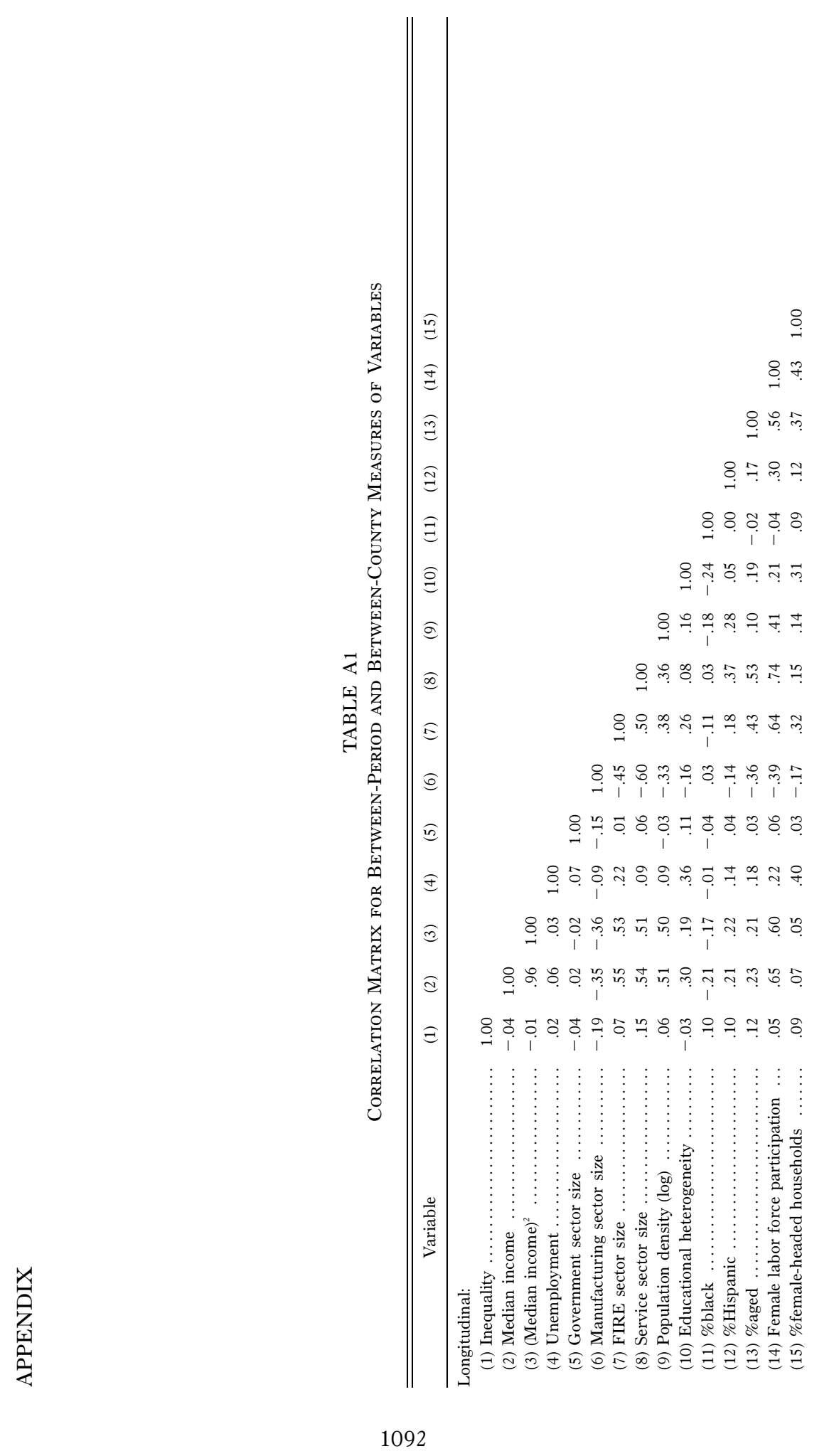




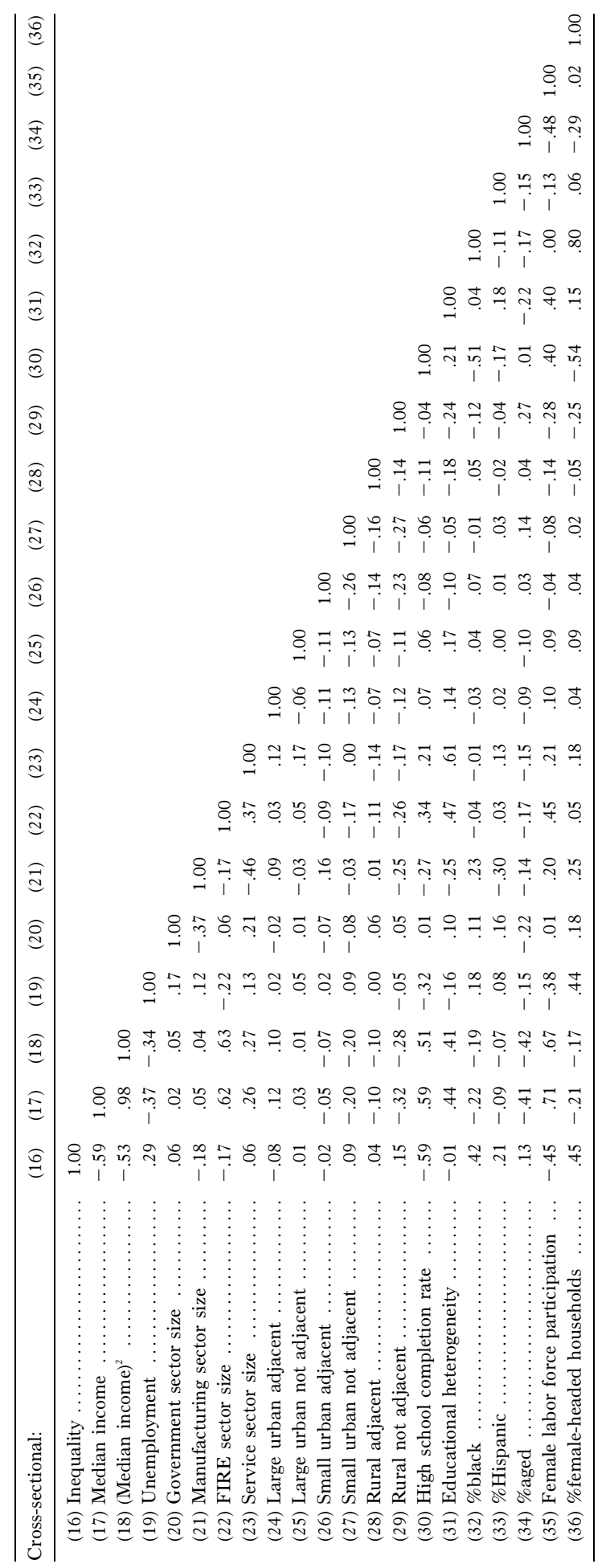

1093 


\section{American Journal of Sociology}

\section{REFERENCES}

Adams, Terry K. 1992a. Census of Population and Housing 1970: Extract Data. Ann Arbor, Mich.: Inter-university Consortium for Political and Social Research.

. 1992b. Census of Population and Housing 1980: Extract Data. Ann Arbor, Mich.: Inter-university Consortium for Political and Social Research.

Alderson, Arthur S. 1999. "Explaining De-industrialization: Globalization, Failure, or Success?" American Sociological Review 64:701-21.

Alderson, Arthur S., Jason Beckfield, and François Nielsen. 2005. "Exactly How Has Income Inequality Changed? Distributional Change in Core Societies." International Journal of Comparative Sociology 46:405-24.

Alderson, Arthur S., and François Nielsen. 2002. "Globalization and the Great U-turn: Income Inequality Trends in 16 OECD Countries." American Journal of Sociology 107:1244-99.

Alperovich, G. 1995. "The Effectiveness of Spline Urban Density Functions: An Empirical Investigation." Urban Studies 32:1537-48.

Amenta, Edwin. 1998. Bold Relief: Institutional Politics and the Origins of Modern American Social Policy. Princeton, N.J.: Princeton University Press.

Autor, David H., Lawrence F. Katz, and Melissa S. Kearney. 2005. "Trends in U.S. Wage Inequality: Re-assessing the Revisionists.” Working paper no. 11627. National Bureau of Economic Research, Cambridge, Mass.

Autor, David H., Lawrence F. Katz, and Alan B. Krueger. 1998. "Computing Inequality: Have Computers Changed the Labor Market?” Quarterly Journal of Economics 113: $1169-1213$

Baccaro, Lucio, and Diego Rei. 2005. "Institutional Determinants of Unemployment in OECD Countries: A Time Series Cross-section Analysis (1960-98)." IILS Decent Work Research Programme working paper no. 160. International Institute for Labour Studies, Geneva.

Baker, Dean, Andrew Glyn, David Howell, and John Schmitt. 2004. "Unemployment and Labor Market Institutions: The Failure of the Empirical Case for Deregulation." Working paper no. 2004-04. International Labour Organization, Geneva.

Bane, Mary Jo. 1988. "Politics and Policies of the Feminization of Poverty." Pp. 381-96 in The Politics of Social Policy in the United States, edited by Margaret Weir, Ann Shola Orloff, and Theda Skocpol. Princeton, N.J.: Princeton University Press.

Beale, Calvin. 2004. "Measuring Rurality: Rural-Urban Continuum Codes." United States Department of Agriculture, Economic Research Service. http://www.ers .usda.gov/briefing/Rurality/RuralUrbCon/.

Berman, Eli, John Bound, and Zvi Griliches. 1994. "Changes in the Demand for Skilled Labor within U.S. Manufacturing: Evidence from the Annual Survey of Manufactures." Quarterly Journal of Economics 114:367-97.

Blalock, H. M. 1957. "Per Cent Non-white and Discrimination in the South." American Sociological Review 22:677-82.

Blank, Rebecca M., ed. 1994. Social Protection versus Economic Flexibility. Chicago: University of Chicago Press.

- 1998. "Contingent Work in a Changing Labor Market." Pp. 258-94 in Generating Jobs: How to Increase Demand for Less-Skilled Workers, edited by Richard B. Freeman and Peter Gottschalk. New York: Russell Sage Foundation.

Blank, Rebecca M., and Alan S. Blinder. 1986. "Macroeconomics, Income Distribution, and Poverty." Pp. 180-208 in Fighting Poverty: What Works and What Doesn't, edited by Sheldon H. Danziger and Daniel H. Weinberg. Cambridge, Mass.: Harvard University Press.

Blau, Francine D., Marianne A. Ferber, and Anne E. Winkler. 2006. The Economics of Women, Men, and Work, 5th ed. Upper Saddle River, N.J. : Pearson/Prentice Hall. 
Blau, Francine D., and Lawrence M. Kahn. 2002. At Home and Abroad: U.S. Labor Market Performance in International Perspective. New York: Russell Sage Foundation.

Bluestone, Barry, and Bennett Harrison. 1982. The Deindustrialization of America: Plant Closings, Community Abandonment, and the Dismantling of Basic Industry. New York: Basic Books.

. 2001. Growing Prosperity: The Battle for Growth and Equity in the Twentyfirst Century. Berkeley and Los Angeles: University of California Press.

Borjas, George J. 1994. "The Economics of Immigration." Journal of Economic Literature 32:1667-1717.

Bound, John, and George Johnson. 1992. "Changes in the Structure of Wages in the 1980s: An Evaluation of Alternative Explanations." American Economic Review 82: 371-92.

Bradley, David, Evelyne Huber, Stephanie Moller, François Nielsen, and John Stephens. 2003. "Distribution and Redistribution in Post-industrial Democracies." World Politics 55:193-228.

Brady, David. 2003. "The Politics of Poverty: Left Political Institutions, the Welfare State, and Poverty." Social Forces 82:557-88.

Brooks, Clem, and Jeff Manza. 2007. Why Welfare States Persist: The Importance of Public Opinion in Democracies. Chicago: University of Chicago Press.

Browne, Irene. 2000. "Opportunities Lost? Race, Industrial Restructuring, and Employment among Young Women Heading Households." Social Forces 78:907-31.

Burtless, Gary, ed. 1996. Does Money Matter? The Effect of School Resources on Student Achievement and Adult Success. Vancouver: University of British Columbia Press.

. 1999. "Effects of Growing Wage Disparities and Changing Family Composition on the U.S. Income Distribution." European Economic Review 43:853-65.

Cancian, Maria, and Deborah Reed. 1999. "The Impact of Wives' Earnings on Income Inequality: Issues and Estimates.” Demography 36:173-84.

- 2001. "Changes in Family Structure: Implications for Poverty and Related Policy." Pp. 69-96 in Understanding Poverty, edited by Sheldon H. Danziger and Robert H. Haveman. New York: Russell Sage Foundation.

Card, David, and John E. DiNardo. 2002. "Skill-Biased Technological Change and Rising Wage Inequality: Some Problems and Puzzles.” Journal of Labor Economics 20:733-83.

Cauthen, Nancy, and Edwin Amenta. 1996. "Not for Widows Only: Institutional Politics and the Formative Years of Aid to Dependent Children." American Sociological Review 61:427-48.

Chiswick, Barry R. 1974. Income Inequality: Regional Analyses within a Human Capital Framework. New York: Columbia University Press.

Cohen, Philip N. 1998. "Black Concentration Effects on Black-White and Gender Inequality: Multilevel Analysis for U.S. Metropolitan Areas." Social Forces 77: 207-30.

Cohen, Philip, and Suzanne M. Bianchi. 1999. "Marriage, Children, and Women's Employment: What Do We Know?" Monthly Labor Review 122:22-31.

Crenshaw, Edward, and Ansari Ameen. 1993. "Dimensions of Social Inequality in the Third World: A Cross-national Analysis of Income Inequality and Mortality Decline." Population Research and Policy Review 12:297-313.

Danziger, Sheldon. 1976. "Determinants of the Level and Distribution of Family Income in Metropolitan Areas, 1969." Land Economics 52:467-78.

Danziger, Sheldon, and Robert Plotnick. 1986. "Poverty and Policy: Lessons of the Last Two Decades." Social Service Review 60:34-51.

DiPrete, Thomas A. 2005. "Labor Markets, Inequality, and Change." Work and Occupations 32:119-39. 


\section{American Journal of Sociology}

DiPrete, Thomas A., Dominique Goux, Eric Maurin, and Amélie Quesnel-Vallée. 2006. "Work and Pay in Flexible and Regulated Labor Markets: A Generalized Perspective on Institutional Evolution and Inequality Trends in Europe and the U.S." Research in Social Stratification and Mobility 24:311-32.

Ebbinghaus, Bernhard, and Bernhard Kittel. 2005. "European Rigidity versus American Flexibility: The Institutional Adaptability of Collective Bargaining." Work and Occupations 32:163-95.

Erikson, Robert S., Gerald C. Wright, and John P. McIver. 1993. Statehouse Democracy: Public Opinion and Policy in the American States. New York: Cambridge University Press.

Esping-Andersen, Gøsta. 1990. The Three Worlds of Welfare Capitalism. Princeton, N.J.: Princeton University Press.

. 1999. Social Foundations of Postindustrial Economies. New York: Oxford University Press.

Farbman, Michael. 1975. "The Size Distribution of Family Income in U.S. SMSAs, 1959." Review of Income and Wealth 21:217-317.

Fiorina, Morris P. 1994. "Divided Government in American States: A Byproduct of Legislative Professionalism.” American Political Science Review 88:304-16.

Firebaugh, Glenn. 2003. The New Geography of Global Income Inequality. Cambridge, Mass.: Harvard University Press.

Freeman, Richard B., and Lawrence E. Katz, eds. 1995. Differences and Changes in Wage Structures. Chicago: University of Chicago Press.

Freeman, Richard B., and James L. Medoff. 1984. What Do Unions Do? New York: Basic Books.

Fry, Brian R., and Richard F. Winters. 1970. "The Politics of Redistribution.” American Political Science Review 64:508-22.

Garofalo, Gasper, and Michael S. Fogarty. 1979. "Urban Income Distribution and the Urban Hierarchy-Equality Hypothesis." Review of Economics and Statistics 61: 381-88.

GeoLytics. 1999. CensusCD 1980. East Brunswick, N.J.: GeoLytics. . 2002. CensusCD 1970. East Brunswick, N.J.: GeoLytics.

Goodin, Robert E., Bruce Headey, Ruud Muffels, and Henk-Jan Dirven. 1999. The Real Worlds of Welfare Capitalism. New York: Cambridge University Press.

Gramlich, Edward M., and Deborah S. Laren. 1984. "How Widespread Are Income Losses in a Recession?" Pp. 157-80 in The Social Contract Revisited: Aims and Outcomes of President Reagan's Social Welfare Policy, edited by D. Lee Bawden. Washington, D.C.: Urban Institute Press.

Gray, Virginia, and Russell L. Hanson. 1999. Politics in the American States, 7th ed. Washington, D.C.: CQ Press.

. 2004. Politics in the American States, 8th ed. Washington, D.C.: CQ Press.

Gray, Virginia, Herbert Jacob, and Robert B. Albritton. 1990. Politics in the American States. Glenville, Ill.: Scott Foresman/Little, Brown Higher Education.

Gray, Virginia, Herbert Jacob, and Kenneth N. Vines. 1983. Politics in the American States. Washington, D.C.: CQ Press.

Gustafsson, Björn, and Mats Johansson. 1999. "In Search of Smoking Guns: What Makes Income Inequality Vary over Time in Different Countries." American Sociological Review 64:585-605.

Hanson, Russell L. 1999. "Intergovernmental Relations." Pp. 32-65 in Politics in the American States: A Comparative Analysis, edited by Virginia Gray, Russell L. Hanson, and Herbert Jacob. Washington, D.C.: CQ Press.

Harrison, Bennett, and Barry Bluestone. 1988. The Great U-turn: Corporate Restructuring and the Polarizing of America. New York: Basic Books.

Hatton, Timothy J., and Jeffrey G. Williamson. 1998. The Age of Mass Migration: Causes and Economic Impact. New York: Oxford University Press. 
Hicks, Alexander, Roger Friedland, and Edwin Johnson. 1978. "Class Power and State Policy: The Case of Large Business Corporations, Labor Unions and Governmental Redistribution in the American States." American Sociological Review 43:302-15.

Hicks, Alexander, and Joya Misra. 1993. "Political Resources and the Growth of Welfare in Affluent Capitalist Democracies, 1960-1982." American Journal of Sociology 99:668-710.

Horney, Julie, D. Wayne Osgood, and Ineke Haen Marshall. 1995. "Criminal Careers in the Short-Term: Intra-individual Variability in Crime and Its Relation to Local Life Circumstances." American Sociological Review 60:655-73.

Huber, Evelyne, François Nielsen, Jenny Pribble, and John D. Stephens. 2006. "Income Inequality and the Welfare State in Contemporary Latin America." American Sociological Review 71 (6): 943-63.

Huber, Evelyne, and John D. Stephens. 2001. Development and Crisis of the Welfare States: Parties and Policies in Global Markets. Chicago: University of Chicago Press.

Jacob, Herbert, and Kenneth N. Vines. 1971. Politics in the American States, 2d ed. Boston: Little Brown.

- 1976. Politics in the American States, 3d ed. Boston: Little Brown

Jacobs, David. 1982. "Competition, Scale and Political Explanations for Inequality: An Integrated Study of Sectoral Explanations at the Aggregate Level." American Sociological Review 47:600-614.

- 1985. "Unequal Organizations or Unequal Attainments? An Empirical Comparison of Sectoral and Individualistic Explanations for Aggregate Inequality." American Sociological Review 50:166-80.

Jacobs, Jerry A., and Mary Blair-Loy. 2001. "Gender, Race, Local Labor Markets, and Occupational Devaluation." Pp. 347-74 in Problem of the Century: Racial Stratification in the United States, edited by Elijah J. Anderson and Douglas S. Massey. New York: Russell Sage Foundation.

Karoly, Lynn A., and Gary Burtless. 1995. "Demographic Change, Rising Earnings Inequality, and the Distribution of Personal Well-being, 1959-1989." Demography 32:379-406.

Kenworthy, Lane. 1999. "Do Social-Welfare Policies Reduce Poverty? A Cross-national Assessment." Social Forces 77:1119-39.

2004. Egalitarian Capitalism: Jobs, Incomes, and Growth in Affuent Countries. New York: Russell Sage Foundation.

Kenworthy, Lane, and Jonas Pontusson. 2005. "Rising Inequality and the Politics of Redistribution in Affluent Countries." Perspectives on Politics 3:449-71.

Key, Valdimer O. 1949. Southern Politics in State and Nation. New York: Knopf.

King, James D. 2000. "Changes in Professionalism in U.S. State Legislatures." Legislative Studies Quarterly 25:327-43.

Korpi, Walter. 1989. "Power, Politics, and State Autonomy in the Development of Social Citizenship: Social Rights during Sickness in Eighteen OECD Countries since 1930." American Sociological Review 54:309-28.

Kuznets, Simon. 1955. "Economic Growth and Income Inequality." American Economic Review 45:1-28.

Lecaillon, Jacques, Felix Paukert, Christian Morrisson, and Dimitri Germidis. 1984. Income Distribution and Economic Development: An Analytical Survey. Geneva: International Labour Office.

Lee, Cheol-Sung. 2005. "Income Inequality, Democracy, and Public Sector Size." American Sociological Review 70:158-82.

Lee, David S. 1999. "Wage Inequality in the United States during the 1980s: Rising Dispersion or Falling Minimum Wage." Quarterly Journal of Economics 114: 977-1023

Leicht, Kevin T., and J. Craig Jenkins. 1998. "Political Resources and Direct State 


\section{American Journal of Sociology}

Intervention: The Adoption of Public Venture Capital Programs in the American States, 1974-1990." Social Forces 76:1323-46.

Levernier, William. 1999. "An Analysis of Family Income Inequality in Metropolitan Counties." Social Science Quarterly 80:154-65.

Levy, Frank, and Richard C. Michel. 1991. The Economic Future of American Families: Income and Wealth Trends. Washington, D.C.: Urban Institute Press.

Levy, Frank, and Richard J. Murname. 1992. "U.S. Earnings Levels and Earnings Inequality: A Review of Recent Trends and Proposed Explanations." Journal of Economic Literature 30:1333-81.

Lindert, Peter H. 2000. "Three Centuries of Inequality in Britain and America." Pp. 167-216 in Handbook of Income Distribution, vol. 1, edited by Anthony B. Atkinson and François Bourguignon. Amsterdam: Elsevier.

Lindert, Peter H., and Jeffrey G. Williamson. 1985. "Growth, Equality, and History." Explorations in Economic History 22:341-77.

Littell, Ramon C., George A. Milliken, Walter W. Stroup, and Russell D. Wolfinger. 1996. SAS System for Mixed Models. Cary, N.C.: SAS Institute.

Lobao, Linda, and Gregory Hooks. 2003. "Public Employment, Welfare Transfers, and Economic Well-being across Local Populations: Does Lean and Mean Government Benefit the Masses?" Social Forces 82:519-56.

Long, James E., David W. Rasmussen, and Charles T. Haworth. 1977. "Income Inequality and City Size." Review of Economics and Statistics 59:244-46.

Lorence, Jon, and Noel Nelson. 1993. "Industrial Restructuring and Metropolitan Earnings Inequality, 1970-1980." Research in Social Stratification and Mobility 12: $145-85$.

Maestas, Cherie. 2000. "Professional Legislatures and Ambitious Politicians: Policy Responsiveness of State Institutions." Legislative Studies Quarterly 25:663-91.

Massey, Douglas S. 2001. "Segregation and Violent Crime in Urban America" Pp. 317-46 in Problem of the Century: Racial Stratification in the United States, edited by Elijah Anderson and Douglas S. Massey. New York: Russell Sage Foundation.

Massey, Douglas S., and Nancy Denton. 1988. "The Dimensions of Residential Segregation." Social Forces 67:281-315.

- 1998. "The Elusive Quest for the Perfect Index of Concentration: Reply to Egan, Anderson and Weber." Social Forces 76:1123-34.

McCall, Leslie. 2001. "Sources of Racial Wage Inequality in Metropolitan Labor Markets: Racial, Ethnic and Gender Differences.” American Sociological Review 66: 520-41.

McLanahan, Sara, Annemette Sorenson, and Dorothy Watson. 1989. "Sex Differences in Poverty, 1950-1980." Signs 15:13-27.

McManus, Patricia A., and Thomas A. DiPrete. 2000. "Market, Family, and State Sources of Income Instability in Germany and the United States." Social Science Research 29:405-40.

Meyer, Robert H., and David A. Wise. 1983. "The Effects of the Minimum Wage on the Employment and Earnings of Youth." Journal of Labor Economics 1:66-100.

Mill, John Stuart. 1848. Principles of Political Economy. London: John Parker \& Son.

Miller, Kathleen K., and Bruce A. Weber. 2004. "Persistent Poverty and Place: How Do Persistent Poverty Dynamics and Demographics Vary across the Rural-Urban Continuum?" Measuring Rural Diversity 1:1-7.

Mincer, J. 1962. "Labor Force Participation of Married Women: A Study of Labor Supply." Pp. 63-106 in Aspects of Labor Economics, edited by the National Bureau of Economic Research. Princeton, N.J.: Princeton University Press.

Moller, Stephanie. 2003. Income and Inequality in the U.S. States. Doctoral dissertation. University of North Carolina, Chapel Hill, Department of Sociology.

. 2008. "Policy Egalitarianism and Household Income: The State and Structural Vulnerability." Research in Social Stratification and Mobility 26:323-40. 
Moller, Stephanie, David Bradley, Evelyne Huber, François Nielsen, and John Stephens. 2003. "Determinants of Poverty in Advanced Capitalist Democracies." American Sociological Review 68:22-51.

Moller, Stephanie, and Huiping Li. In press. "The State and Inequality: The Political Determinants of Occupational Sex Segregation in the United States." Social Forces.

Morris, Martina, and Bruce Western. 1999. "Inequality in Earnings at the Close of the 20th Century." Annual Review of Sociology 25:623-57.

Nielsen, François. 1994. "Income Inequality and Industrial Development: Dualism Revisited." American Sociological Review 59:654-77.

Nielsen, François, and Arthur S. Alderson. 1995. "Income Inequality, Development, and Dualism: Results from an Unbalanced Cross-national Panel." American Sociological Review 60:674-701.

- 1997. "The Kuznets Curve and the Great U-turn: Income Inequality in U.S. Counties, 1970 to 1990." American Sociological Review 62:12-33.

- 2001. "Trends in Income Inequality in the United States." Pp. 355-85 in Sourcebook on Labor Markets: Evolving Structures and Processes, edited by Ivar Berg and Arne L. Kalleberg. New York: Plenum.

Nord, Stephen. 1980. "An Empirical Analysis of Income Inequality and City Size." Southern Economic Journal 46:863-72.

- 1982. "Urban Income Distriubtion and the Urban Hierarchy-Equality Hypothesis: A Comment." Review of Economics and Statistics 64:537-40.

Orloff, Ann Shola, and Theda Skocpol. 1984. "Why Not Equal Protection? Explaining the Politics of Public Social Spending in Britain, 1900-1911, and the United States, 1880s-1920." American Sociological Review 49:726-50.

Page, Benjamin, and James Simmons. 2000. What Government Can Do: Dealing with Poverty and Inequality. Chicago: University of Chicago Press.

Powell, Walter W., and Paul J. DiMaggio. 1991. The New Institutionalism in Organizational Analysis. Chicago: University of Chicago Press.

Quadagno, Jill. 1987. "Theories of the Welfare State." Annual Review of Sociology 13: 109-28.

Raudenbush, Stephen W., and Anthony Bryk. 2002. Hierarchical Linear Models. Newbury Park, Calif.: Sage Publications.

Ricketts, Thomas C., Karen D. Johnson-Webb, and Patricia Taylor. 1998. "Definitions of Rural: A Handbook for Health Policy Makers and Researchers.” Technical issues paper prepared for the Federal Office of Rural Health Policy, Health Resources and Services Administration. University of North Carolina, Chapel Hill, Cecil G. Sheps Center for Health Services Research.

Sassen, Saskia. 1998. Globalization and Its Discontents. New York: New Press.

. 2001. The Global City: New York, London, Tokyo, 2d ed. Princeton, N.J.: Princeton University Press.

Simpson, Miles. 1990. "Income Inequality: A Cross-national Test." American Sociological Review 55 (5): 682-93.

Singelmann, Joachim, Forrest A. Deseran, F. Carson Mencken, and Jiang Hong Li. 1993. "What Drives Labor Market Growth: Economic Performance of Labor Market Areas: 1980-86." Pp. 33-49 in Inequalities in Labor Market Areas, edited by Joachim Singelmann and Forrest A. Deseran. Boulder, Colo.: Westview Press.

Skocpol, Theda. 1985. "Bringing the State Back In: Strategies of Analysis in Current Research." Pp. 3-43 in Bringing the State Back In, edited by Peter B. Evans, Dietrich Rueschemeyer, and Theda Skocpol. New York: Cambridge University Press. Press.

- 1992. Protecting Soldiers and Mothers. Cambridge, Mass.: Harvard University

Skocpol, Theda, and Edwin Amenta. 1986. "States and Social Policies." Annual Review of Sociology 12:131-57. 


\section{American Journal of Sociology}

Smeeding, Timothy M. 1992. "Why the U.S. Antipoverty System Doesn't Work Very Well." Challenge 35:30-35.

Soule, Sarah A., and Yvonne Zylan. 1997. "Runaway Train? The Diffusion of StateLevel Reform in ADC/AFDC Eligibility Requirements, 1950-1967." American Journal of Sociology 103:733-62.

Stephens, John. 1979. The Transition from Capitalism to Socialism. Urbana: University of Illinois Press.

Stigler, George J. 1946. "The Economics of Minimum Wage Legislation." American Economic Review 36:358-65.

Theil, Henri. 1972. Statistical Decomposition Analysis. Amsterdam: North-Holland.

Thurow, Lester C. 1987. "A Surge in Inequality." Scientific American 256:30-37.

Tienda, Marta, Shelley A. Smith, and Vilma Ortiz. 1987. "Industrial Restructuring, Gender Segregation, and Sex Differences in Earnings." American Sociological Review 52:195-210.

Tinbergen, Jan. 1975. Income Distribution: Analysis and Policies. Amsterdam: NorthHolland.

Tobin, James. 1994. "Poverty in Relation to Macroeconomic Trends, Cycles, and Policies." Pp. 147-67 in Confronting Poverty: Prescriptions for Change, edited by Sheldon Danziger, Gary D. Sandefur, and Daniel H. Weinberg. New York: Russell Sage Foundation.

Tomaskovic-Devey, Donald, and Vincent Roscigno. 1996. "Racial Economic Subordination and White Gain in the U.S. South." American Sociological Review 61:565-89.

U.S. Bureau of the Census. 1970. Census of the Population. Washington, D.C.: Government Printing Office.

. 1978. County and City Data Book Consolidated File, County Data, 1944-1977. Washington, D.C.: U.S. Bureau of the Census. Office.

. 1980. Census of the Population. Washington, D.C.: Government Printing

1984. County and City Data Book, 1983 Files on Tape. Washington, D.C.: U.S. Bureau of the Census.

- 1990. Census of the Population. Washington, D.C.: Government Printing Office.

1991. Census of Population and Housing, 1990: Summary Tape File 3 (U.S.).

Washington, D.C.: U.S. Bureau of the Census.

1992. County Statistics File 4. Washington, D.C.: Government Printing Office.

- 1998. Measuring 50 Years of Economic Change Using the March Current Population Survey. Current Population Reports no. P60-203. Washington, D.C.: U.S. Bureau of the Census.

2000. Census of Population and Housing, 2000: Summary File 3. Washington, D.C.: U.S. Bureau of the Census.

Census.

- 2006. Current Population Survey: March Annual Social and Economic Supplement. Washington, D.C.: U.S. Bureau of the Census.

- Various years. Statistical Abstract of the United States. Washington, D.C.: Government Printing Office.

U.S. Department of Labor. 2006. Changes in Basic Minimum Wages in Non-farm Employment under State Law: Selected Years, 1968 to 2006. Washington, D.C.: U.S. Department of Labor.

Volscho, Thomas W. 2005. "Minimum Wages and Income Inequality in the American States, 1960-2000." Research in Social Stratification and Mobility 23:343-68.

Wallerstein, Michael. 1999. "Wage-Setting Institutions and Pay Inequality in Advanced Industrial Societies.” American Journal of Political Science 43:649-80. 
Income Inequality

Weber, Ronald E. 1999. "The Quality of State Legislative Representation: A Critical Assessment." Journal of Politics 61:609-27.

Weir, Margaret, Ann Shola Orloff, and Theda Skocpol. 1988. The Politics of Social Policy in the United States. Princeton, N.J.: Princeton University Press.

Williamson, Jeffrey G., and Peter H. Lindert. 1980. American Inequality: A Macroeconomic History. New York: Academic Press.

Wilson, William Julius. 1987. The Truly Disadvantaged: The Inner City, the Underclass and Public Policy. Chicago: University of Chicago Press.

Wimberley, Ronald C., and Libby V. Morris. 1997. The Southern Black Belt: A National Perspective. Lexington: TVA Rural Studies/University of Kentucky.

Wood, Adrian. 1994. North-South Trade, Employment and Inequality: Changing Fortunes in a Skill-Driven World. Oxford: Clarendon Press. 